\title{
A Comprehensive biological and physico-chemical characteri- zation of humic and fulvic acids nanoparticles as a perspective drug
}

\author{
Elena V. Uspenskaya ${ }^{1,}{ }^{*}$, Tatiana V. Pleteneva ${ }^{1}$, Tatiana V. Grebennikova ${ }^{2}$, Ilaha V. Kazimova ${ }^{1}$, Irina T. Fedyakina ${ }^{2}$, \\ Varvara V. Lebedeva ${ }^{2}$, Oleg E. Latyshev ${ }^{2}$, Olesia V. Eliseeva ${ }^{2}$, Viktor F. Larichev ${ }^{2}$, Timur M. Garaev ${ }^{2}$, Tatiana V. \\ Maximova ${ }^{1,}$ Mariya A. Morozova ${ }^{1,}$ Pham My Hang ${ }^{1,}$ and Anton V. Syroeshkin ${ }^{1}$
}

\footnotetext{
RUDN University, Department of Pharmaceutical and Toxicological Chemistry, Medical Institute, 117198,6 Miklukho-Maklaya Street, Moscow, Russia; uspenskaya75@mail.ru

2 Federal Government Budgetary Institution "National Research Center for Epidemiology and Microbiology named after Honorary Academician N.F. Gamaleya" of the Ministry of Health of the Russian Federation; t grebennikova@mail.ru

* Correspondence: uspenskaya75@mail.ru; Tel.: (+7-916-655-79-86)
}

\begin{abstract}
This work presents the results of a comprehensive physico-chemical and biological study of humic substances samples - an extract of humic and fulvic acids. The performed loss on drying test showed a 22 times different dry matter content between EHS and FA. The morphology and distribution of particles in the dry residue of the samples assessed using the methods of optical and digital microscopy demonstrated differences in the qualitative features of the microstructures of their surfaces and granulometries. Shimadzu X-ray fluorescence spectrometry revealed Si (8.1 and 1.7\%), P (33.5 and 2.7\%), S (4.3 and 59.5\%), K (1.35 and 2.5\%), Ca (10.9 and 3.2\%), Mn (0.27 and $0.06 \%), \mathrm{Fe}(11$ and $0.05 \%), \mathrm{Cu}(0.16$ and $0.45 \%), \mathrm{Zn}(0.06$ and $0.02 \%)$ in the dry residues of the EHS and FA samples, respectively. A high intensity of the X-ray fluorescence signal for Fe atoms in the EHS sample was demonstrated. The FT-IR spectra for EHS and FA are characterized by similar vibration frequencies that are characteristic of the chromone derivatives (1-benzopyran-4-one). The UV absorption spectrum is characterized by $\lambda_{\max }=281 \mathrm{~nm}$ for FA. The EHS solution showed a fluorescence maximum at $\lambda_{\mathrm{em}}=560 \mathrm{~nm}$ at $\lambda_{\mathrm{ex}}=280 \mathrm{~nm}$. Using the DLS method, nanoparticles of $1 \mathrm{~nm}$ and $200 \mathrm{~nm}$ were detected in EHS and FA diluted solutions, which are likely to condition the biochemical and physical properties of humic acids. Using the Spirotox-test method, the absence of the toxic effect of humic acids on the cell model of ciliates Sp. ambigua was established. When the cell model was incubated in a solution of a toxicant of the fluoroquinolone group, a decrease in toxicity was demonstrated when diluted with the EHS solution. The results of the study of the antiviral activity of EHS and FA showed that the study objects in the culture of Vero-E6 cells, in doses nontoxic to cells, suppress the reproduction of the SARS-CoV-2 virus both in the study of the virucidal effect and in the study of the antiviral activity according to the therapeutic and prophylactic model scheme of injection. The results obtained suggest that standardized drugs based on humic acids may open up new perspectives in their biomedical application as antiviral drugs.
\end{abstract}

Keywords: extract of humic substances; fulvic acid; standardization; nanoparticles of polyelectrolytes; antiviral activity; SARS-CoV-2; VERO-E6; Spirotox-method.

\section{Introduction}

Humic substances (HS) are complex, heterogeneous, polydisperse mixtures formed in soils, sediments and natural waters as a result of biochemical reactions during the decomposition and transformation of plant and microbial residues (humification) [1]. The first mention of the important role of humic substances in the functioning of plants and 
animals is found in the works dated 1761 on agronomic chemistry by the Swedish professor of medicine Johan Gottschalk Wallerius. However, all subsequent decades up to the middle of the 20th century were accompanied by the accumulation of empirical knowledge about the biological role of humic substances in natural soil-forming processes. It was shown that HS are characterized by specificity of composition, structure, properties, depending on the conditions and place of their formation [2-6]. Important components of the humification process are plant lignin, its conversion products, polysaccharides, melanin, cutin, proteins, nucleic acids, and lipids [7]. According to [8], the structure of humic substances as polyfunctional compounds does not have a constant chemical composition, which is explained by the stochastic nature of humification processes [9]. Humic substances are extracted from the soil in the form of alkaline solutions, then subjected to fractionation into humic (HA) and fulvic acids (FA), depending on their different solubility in water [10]. Humic and fulvic acids (fulvus - red-yellow) are the most reactive components of humic substances, hypothetical structural models of which are described in [11-13]. Molecules of humic substances of different molecular weights can bind and form a supramolecular humic structure; the degree of aggregation depends on the $\mathrm{pH}$, ionic strength, and mineral composition of the solution [14]. They are therefore classified as polyelectrolytes (Figure 1).

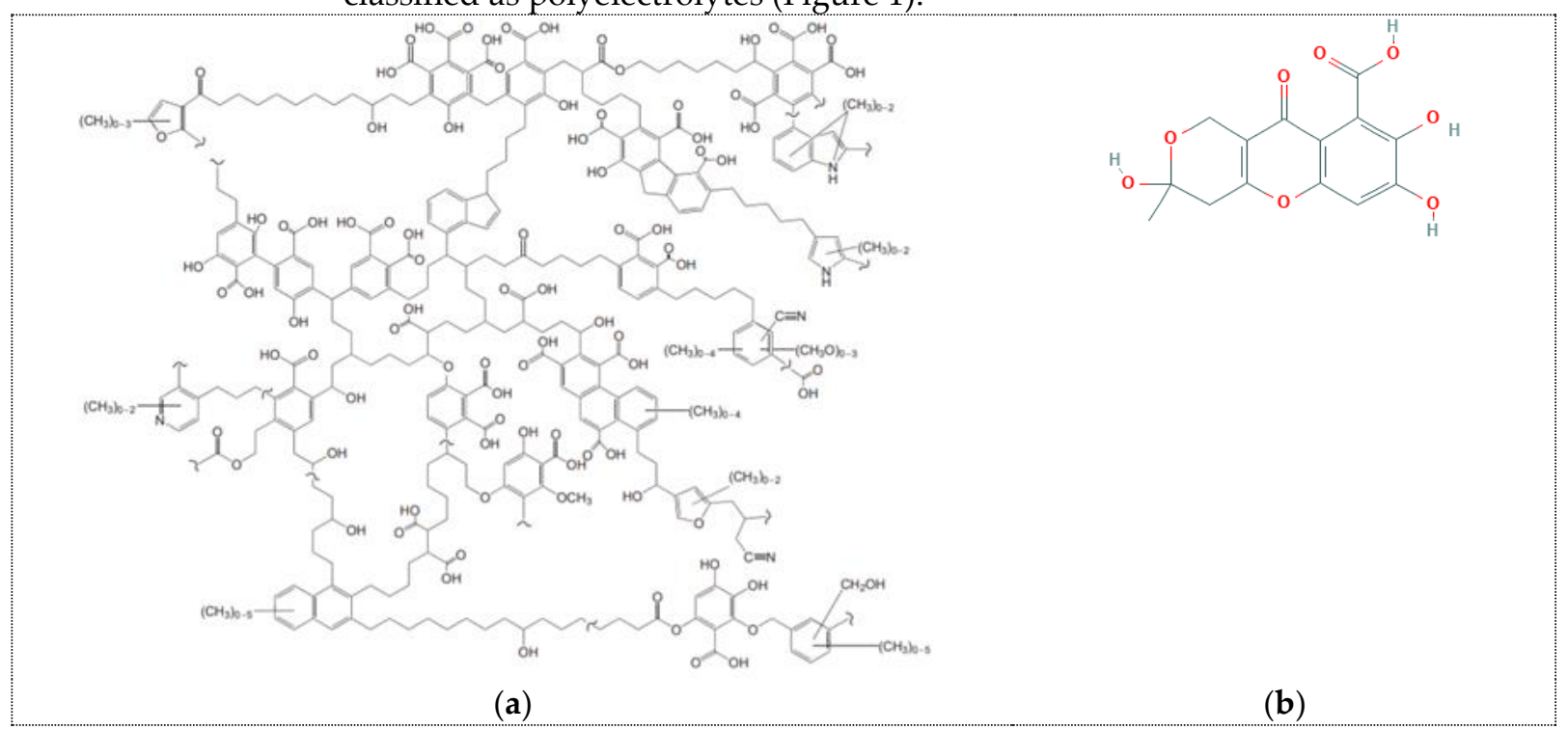

Figure 1. Hypothetical molecular structure: (a) of Humic acid molecules; (b) Fulvic acid; IUPAC Name (3,7,8-trihydroxy3-methyl-10-oxo-1,4-dihydropyrano[4,3-b] chromene-9-carboxylic acid); M.m.= $308.24 \mathrm{~g} / \mathrm{mol}$ [15].

As can be seen in Figure 1, humic substances belong to anionic polyelectrolytes, since they contain polar functional groups in their structure - carboxyl, hydroxyl (alcohol, phenolic) ones, able to dissociate with the formation of negatively charged particles. The described property determines the ability of HS to form complexes with heavy metal ions like the Lewis acid-base reaction [16]. The ability of HS to occlude metals determines the content of micronutrients in their solutions in bioavailable forms, as well as the plant metabolism. According to [17], HS are able to immobilize heavy metals and increase their migration ability. The authors of [18] demonstrated a high efficiency of extraction of precious metals (gold and platinum group elements, PGE) from alkaline extracts of HS brown coal, in which highly dispersed particles of elemental gold were stabilized by humic and fulvic acids.

In recent decades, there have appeared numerous publications about studies of the pharmacological activity of HS and FA against human immunodeficiency virus HIV-1 [19], influenza virus [20], herpes simplex virus-1 (HSV-1) [21], tick-borne encephalitis vi- 
rus (TBEV) [22], bacteria Enterococcus faecalis and Klebsiella pneumoniae [23], and phytopathogenic fungi [24]. The authors demonstrated a much higher activity of the humic acids versus fulvic acids: $\mathrm{HA}>\mathrm{HMA}>\mathrm{FA}$, as well as the dependence on the source of the humic acid release: coal $>$ peloid $>$ peat. The significant role of active components - aliphatic fragments (for $\mathrm{HA}$ ) and $\mathrm{COOH}, \mathrm{OH}$ fragments (for $\mathrm{FA}$ ), which determine a positive correlation with the inhibition rates of HAs and FAs against phytopathogenic fungi, is discussed. The both sequences follow the trend in lipophilicity index (a ratio of aromatic to aliphatic carbon) for these humic materials [25]. Review publications describe the possible mechanisms of HS and FA effect in preventing the replication of the SARS CoV-2 virus by sorption on the virus envelope protein and thereby blocking the sorption of viral particles on the cell surface [26]. Here are currently no drugs that have shown clear and consistent benefits in treating SARS CoV-2, but numerous trials in different countries are underway suggesting that HS may reduce symptoms.

All these data create prerequisites for the creation of new biologically active substances based on natural polyelectrolytes for the pharmaceutical industry. However, the official use of humic preparations in medicine is limited by the lack of registered drugs based on them, due to the complexity of their standardization. For this reason, solving the problem of HS standardization by methods of physico-chemical and biological study is an urgent task of the modern pharmacy.

The purpose of this work is a comprehensive study of solutions and dry matters of humic, fulvic acids by physico-chemical and biological methods for the development of a promising drug for SARS CoV-2.

\section{Results}

\subsection{Determination of dry residue}

Since the determination of dry matter in a liquid sample gives a more convenient idea of the chemical composition of the analyzed material, and also allows comparing different samples with similar physico-chemical properties, we carried out a test to determine the content of the residue after drying samples of humic acid (EHS) and fulvic acid (FA) extracts to a constant mass (Figure 2).

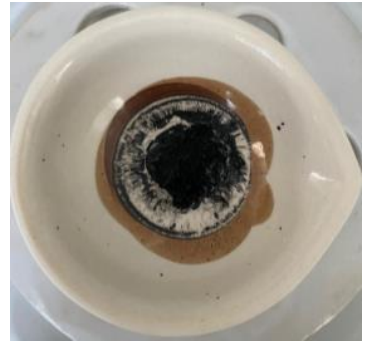

(a)

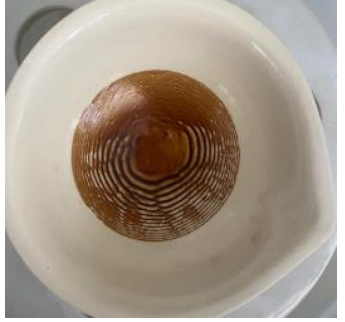

(b)

Figure 2. Dry residue: (a) extract of humic acids; (b) fulvic acid.

The tests carried out in accordance with [27] resulted in the determination of the dry residue $-7.34 \cdot 10^{-2} \mathrm{~g} / \mathrm{ml}$ and $3.36 \cdot 10^{-3} \mathrm{~g} / \mathrm{ml}$, as well as weight loss due to water and volatile substances, which was $92.63 \%$ and $99.66 \%$, respectively, for EHS and FA. Thus, the EHS and FA samples differ from each other in terms of the content of soluble compounds and dry residue.

\subsection{Optical microscopy}

Since the shape, color and size of crystals of a solid are its individual characteristics [28], we studied the morphology and particle distribution of dry samples, invisible to the naked eye, using optical and portable digital microscopy (Figure 3). 


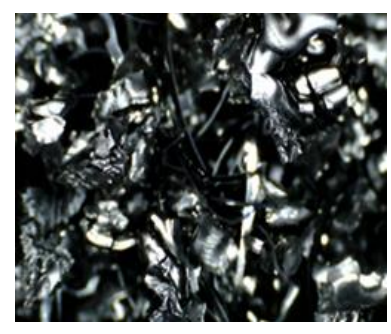

(a)

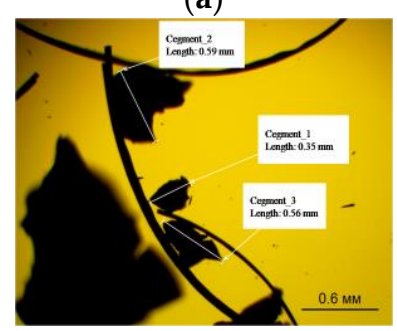

(c)

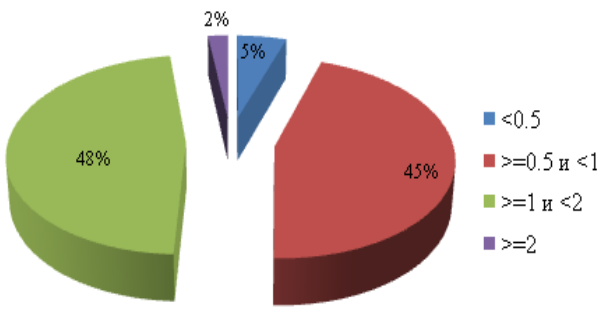

(e)

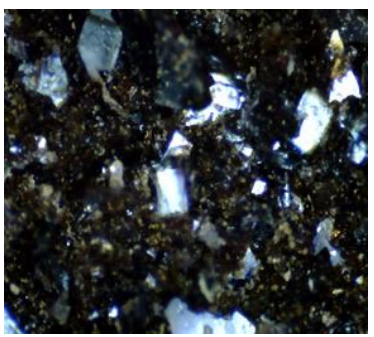

(b)

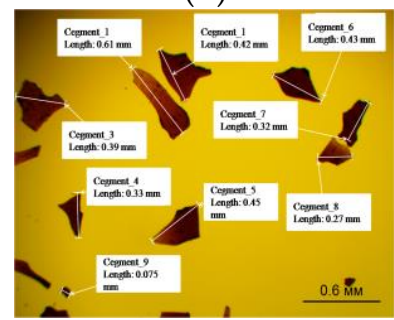

(d)

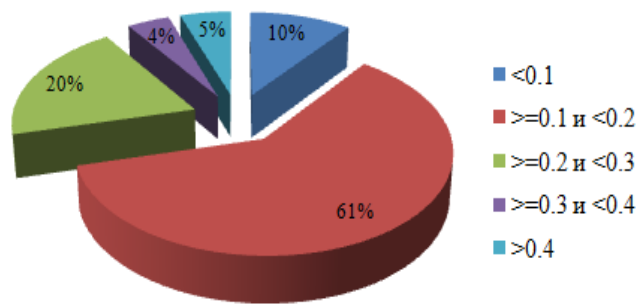

(f)

Figure 3. Morphology and particle size distribution in dry samples: (a), (c), (e) extract of humic acids; (b), (d), (f) fulvic acid.

It can be seen that the EHS sample contains several mineral phases with different particle shapes (crystals, fragmental particles, complex agglomerates, extended linear structures), a large proportion of which, $48 \%$ and $45 \%$, are particles from 0.5 to $2 \mathrm{~mm}$ ). The FA dry residue sample is a highly dispersed, homogeneous micro-aggregate composition, a large proportion $(61 \%)$ of which does not exceed $0.1 \mathrm{~mm}$. When viewed through a binocular lens, FA particles are homogeneous, rounded fragments of minerals.

The analysis and digital visualization [29] of the surface relief of the EHS and FA samples demonstrate differences in the qualitative features of their surface microstructure: elongated bodies, accumulation of discrete mineral fragments in the EHS.

\subsection{Spectroscopy}

\subsubsection{X-ray fluorescence spectrometry - elemental analysis}

Using energy dispersive $X$-ray fluorescence (EDXRF), the elemental composition of the test samples in the residue after drying was evaluated (Figure 4). 


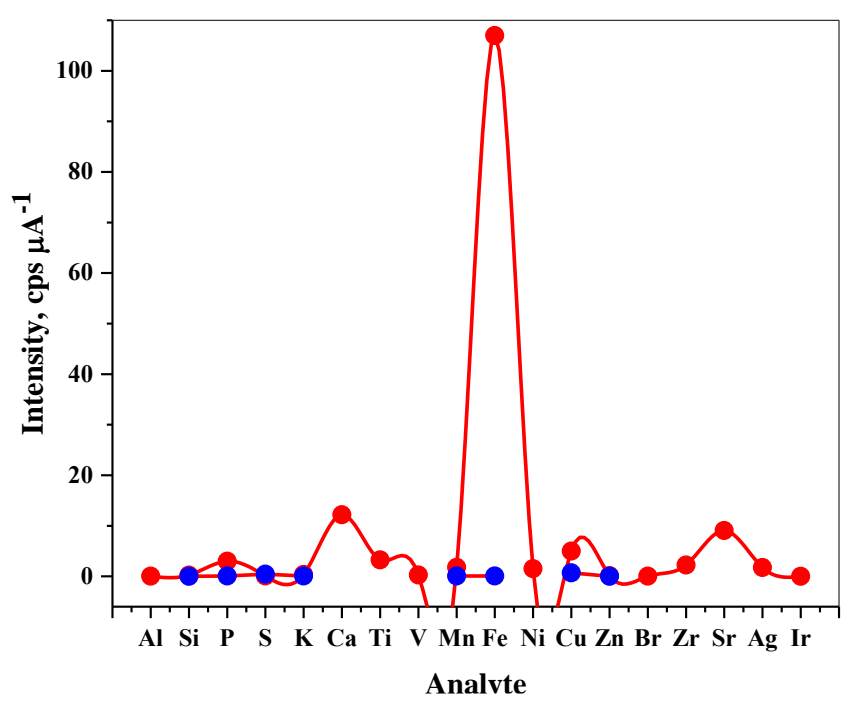

(a)

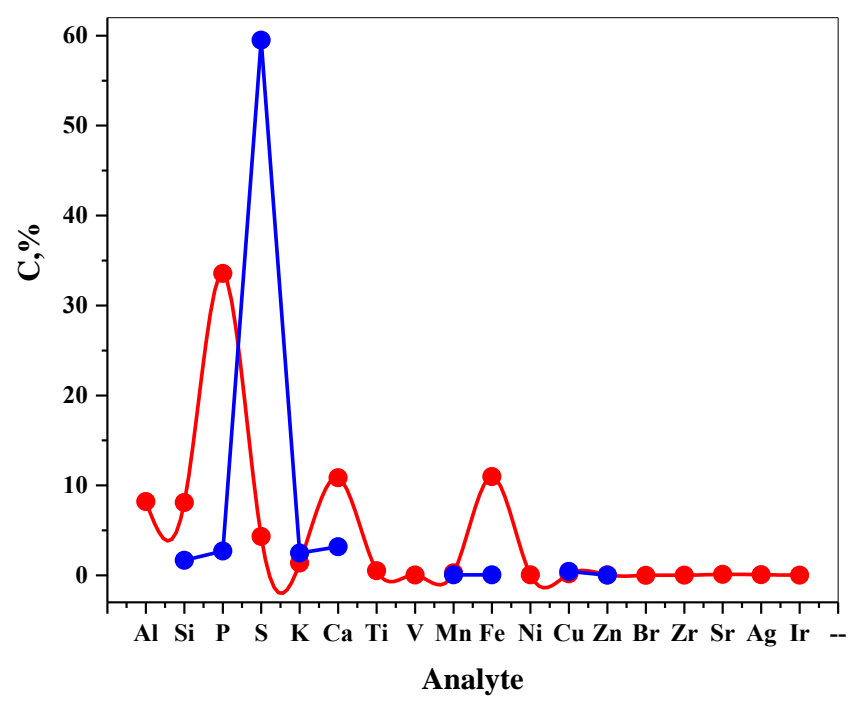

(b)

Figure 4. X-Ray fluorescence analisys of the elements in dry residue of EHS (red) and FA (blue) samples: (a) intensity dependence ; (b) dependence on element fraction.

As can be seen in Figure 4, atoms of the elements $\mathrm{Si}, \mathrm{P}, \mathrm{S}, \mathrm{K}, \mathrm{Ca}, \mathrm{Mn}, \mathrm{Fe}, \mathrm{Cu}, \mathrm{Zn}$ were found in both EHS and FA samples. Noteworthy is the high intensity of the X-ray fluorescence signal for Fe atoms in the EHS sample. It is known that humic substances, participating in the formation of chelates with iron, contribute to plant nutrition [30]. Depending on the solubility and molecular size of HS, humified fractions of organic matter in soil sediments contribute to the creation of a Fe reservoir available to plants [31]. It has been shown [32-33] that the distribution and release of Fe within plants can be controlled if they are supplied with water-soluble Fe-HS complexes in comparison with other natural or synthetic chelates. In case of Fe, highly stable HS complexes mainly include O-containing groups (carboxyl and phenolic) [34]. Fulvic acids are less prone to the formation of insoluble complexes with metals.

\subsubsection{Fourier Transform Infrared (FT-IR) Spectroscopy}

The vibrational-rotational spectra of the EHS and FA samples obtained by the disk technique with potassium bromide are shown in Figure 5.

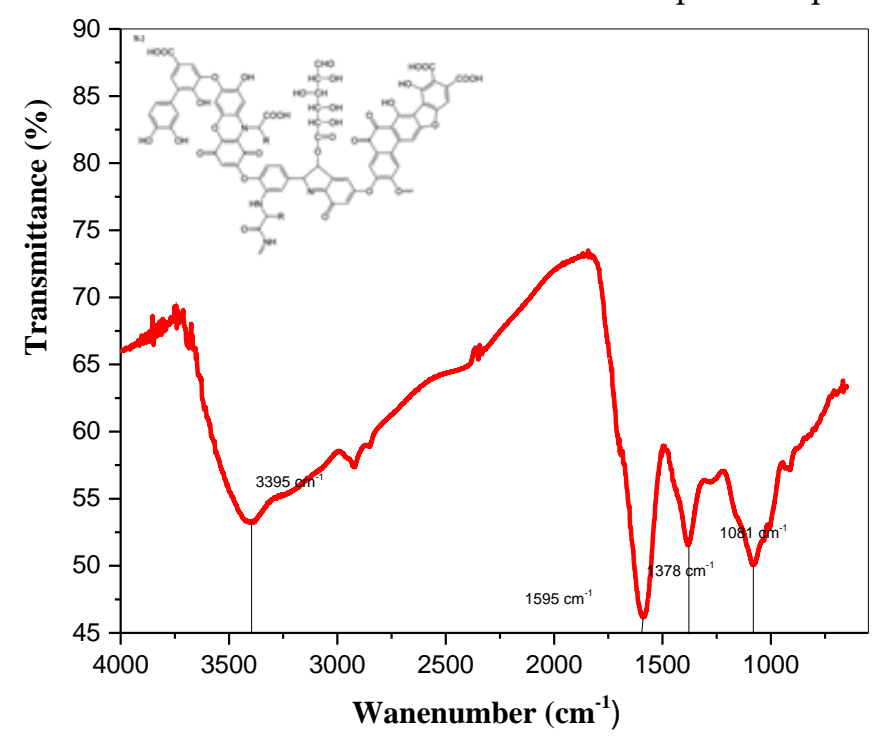

(a)

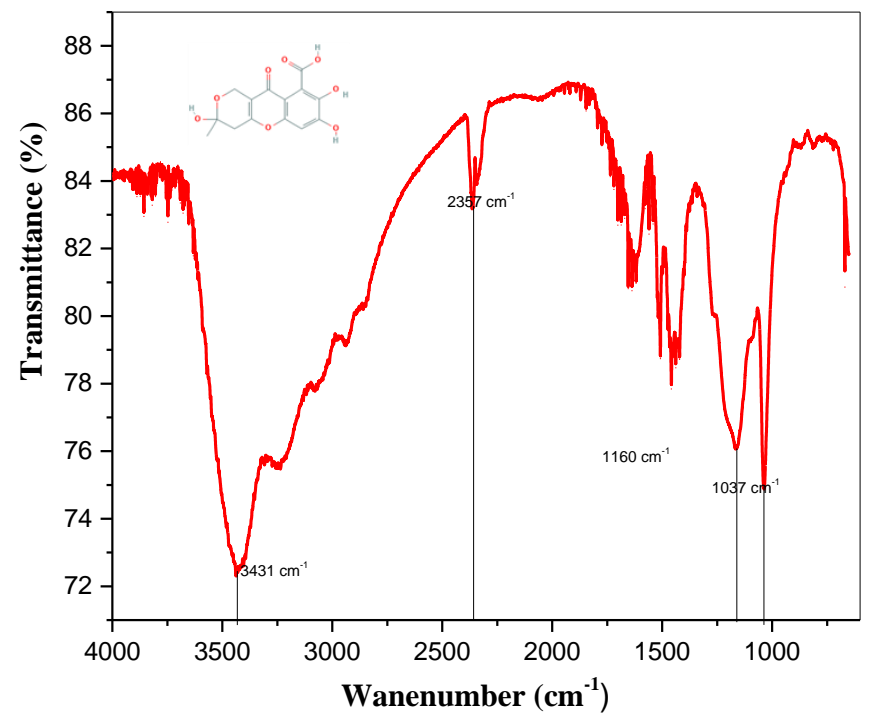

(b) 
Figure 5. FT-IR (Fourier Transform Infrared Spectroscopy) spectrum of: (a) Extract of humic substances; (b) Fulvic acid sample.

The analysis of the IR spectra of the samples under investigation showed the presence of characteristic light transmission bands corresponding to vibrations of bonds between atoms in the structural fragments of alcohol and phenolic hydroxyls, cyclic ethers, carbonyls, and numerous methylene groups [35].

The EHS spectrum is represented by several characteristic bands at 3395, 1595, 1378, and $1081 \mathrm{~cm}^{-1}$. In a comparative analysis of the transmission spectra of the compounds under investigation, it was found that the EHS sample is characterized by higher values of the extinction coefficients, as a result of which the percentage of light transmission is noticeably reduced, which is probably caused by the nonstoichiometric composition and irregular heterogeneous structure with numerous functional groups. Stretching vibrations of free and bound hydroxyl groups $(\mathrm{OH})$ usually form a broadband region in the frequency range from $3200-3670 \mathrm{~cm}^{-1}$ [36]. However, due to the coordinating influence of iron atoms present in the EHS composition and the formation of complex nanostructures containing Me-O bonds, the vibrations of the $\mathrm{O}-\mathrm{H}$ bond can be shifted to the lowfrequency region $\left(\approx 3400 \mathrm{~cm}^{-1}\right)$. In addition, the stretching vibrations of primary or associated amino groups and, probably, imines, can also be attributed to the absorption band at $\approx 3400 \mathrm{~cm}^{-1}$. The presence of a carbon skeleton manifests itself as a band of stretching vibrations of the $\mathrm{C}-\mathrm{H}$ bond at 2900 and $2850 \mathrm{~cm}^{-1}$ [37] (Table 1).

Table 1. The main transmittance bands in the IR spectrum of EHS and FA.

\begin{tabular}{|c|c|c|c|}
\hline $\begin{array}{l}\text { Frequency } \\
\text { Range, } \mathbf{c m}^{-1}\end{array}$ & Group & Compound Class & $\begin{array}{l}\text { Appearance/ } \\
\text { Comments }\end{array}$ \\
\hline \multicolumn{4}{|c|}{ Extract humic substances (HS) } \\
\hline $3550-3200$ & O-H stretching & alcohol & strong, broad/ \\
\hline $2920-2850$ & C-H stretching & alkane & $\begin{array}{l}\text { medium/ } \\
\text { bands due to Fe nano- } \\
\text { spheres [37] }\end{array}$ \\
\hline $1650-1580$ & $\mathrm{~N}-\mathrm{H}$ bending & amine & medium \\
\hline $1690-1640$ & $\mathrm{C}=\mathrm{O}$ stretching & conjugated ketone & strong \\
\hline $1390-1310$ & $\mathrm{O}-\mathrm{H}$ bending & phenol & medium \\
\hline $1085-1050$ & C-O stretching & primary alcohol & strong \\
\hline \multicolumn{4}{|c|}{$\begin{array}{l}\text { Fulvic acid (FA) } \\
\end{array}$} \\
\hline $3550-3200$ & O-H stretching & alcohol & $\begin{array}{l}\text { strong, broad } \\
\text { intermolecular bonded }\end{array}$ \\
\hline $3100-3000$ & C-H stretching & alkene & medium \\
\hline $2920-2850$ & C-H stretching & alkane & $\begin{array}{c}\text { medium/ } \\
\text { нөдөєы, вызваншые- } \\
\text { нанөсферамн bands } \\
\text { due to Fe nanospheres }\end{array}$ \\
\hline $2275-2250$ & $\mathrm{~N}-\mathrm{C}=\mathrm{O}$ stretching & amide & strong, broad \\
\hline $1650-1566$ & $\mathrm{C}=\mathrm{C}$ stretching & cyclic alkene & medium \\
\hline $1440-1395$ & $\mathrm{O}-\mathrm{H}$ bending & carboxylic acid & medium \\
\hline 1450 & C-H bending & alkane & methyl group \\
\hline $1275-1200$ & C-O stretching & alkyl aryl ether & strong \\
\hline $1085-1050$ & C-O stretching & primary alcohol & strong \\
\hline
\end{tabular}


The obtained vibrational-rotational spectra are determined by the structure of the molecules of humus acids, they are characterized by similar vibration frequencies, the shape of the passbands characteristic of the derivatives of benzo- $\gamma$-pyrone (chromone (1benzopyran-4-one). Thus, the infrared spectroscopy method allowed to confirm structural features of investigated compounds [38-39].

\subsubsection{Fluorescence (FL) and ultraviolet (UV)-Spectroscopy}

It is well known that compounds, which are concentrated benzene nuclei with oxidized pyran (coumarins, chromones), are fluorophores or chromophores due to their high photostability, large Stokes shift, and intense fluorescence with a high quantum yield [4042]. The electronic absorption and fluorescence emission spectra of aqueous dilution of the FA and EHS liquid samples are shown in Figure 6. The fluorescence spectra, which are a tool for investigating the effect of the fulvate chromone structure on its optical properties, were recorded at their own excitation wavelength.

As follows from Figure 6 (a), the maximum absorption of fulvate is $281 \pm 2 \mathrm{~nm}$, which is associated with the presence of a chromone heterocyclic nucleus in the structure. As a small organic fluorophore containing several condensed nuclei in a fluorescent open form (see Figure 1 (b), the fulvate molecule produces intense violet $(360 \mathrm{~nm}$ ) and low-intensity green $(560 \mathrm{~nm})$ fluorescence at an excitation wavelength of $280 \mathrm{~nm}$. The emission peaks in the short- and long-wavelength regions of the FL spectrum can be caused by excited state intramolecular proton transfer (ESIPT), which is characteristic of fragments with intramolecular hydrogen bonds [43].

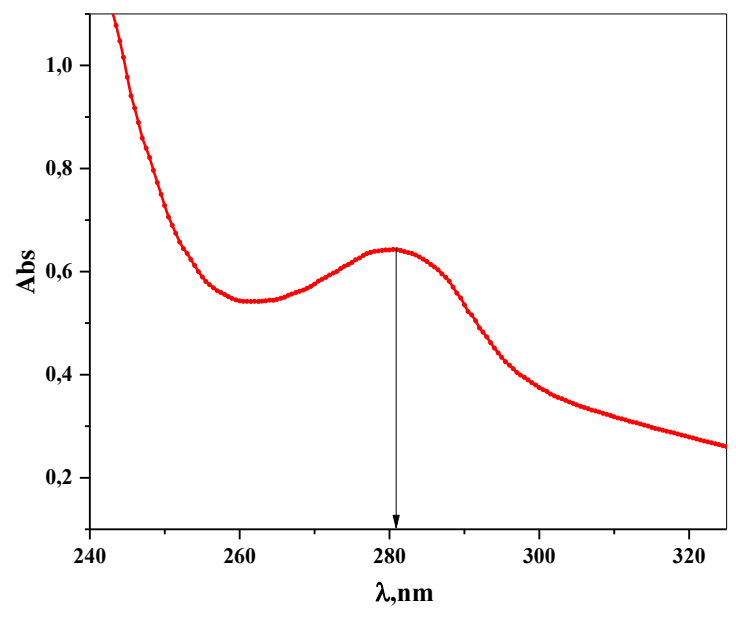

(a)

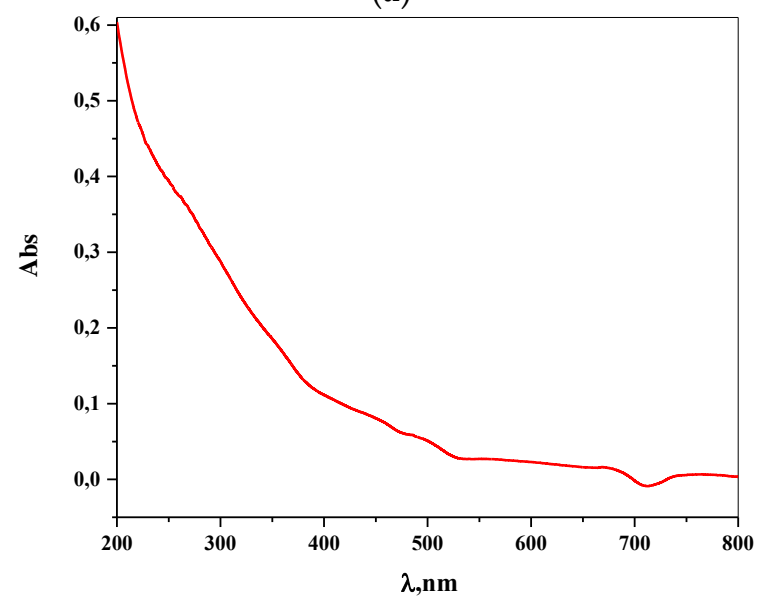

(c)

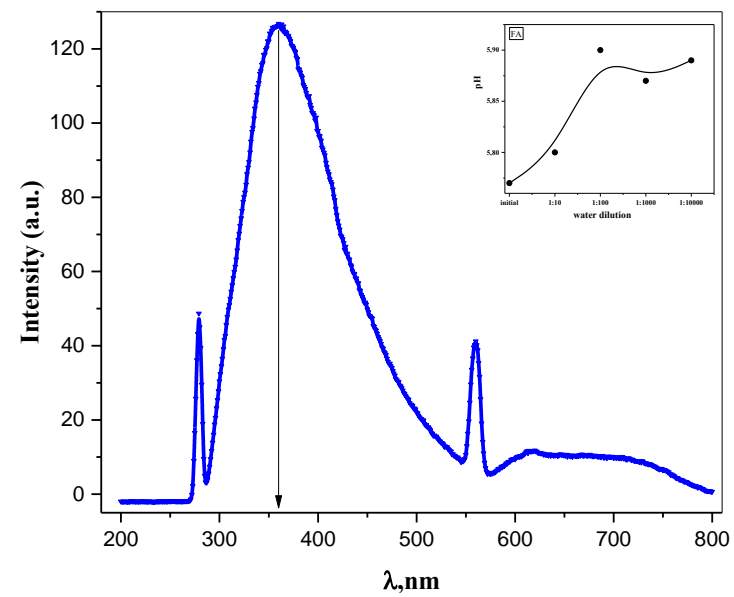

(b)

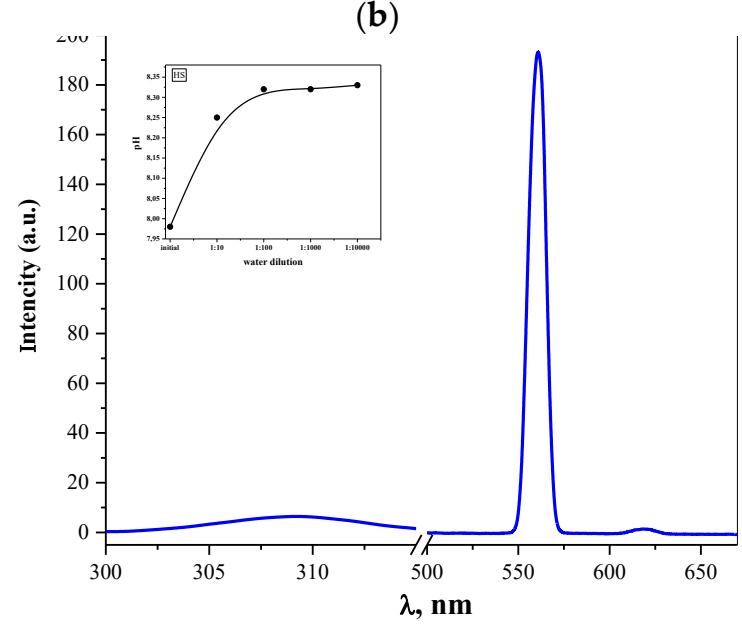

(d) 
Figure 6. Fluorescence and ultraviolet spectrum at the excitation wavelength of $280 \mathrm{~nm}$ and UV: (a), (b) fulvic acid sample water solution (1:100); (c), (d) extract humic substances sample water solution (1:1012). $\mathrm{pH}$ Dependence of dilutions are shown in the inserts.

Since the EHS solution demonstrated near-ultraviolet transparency and increased far-ultraviolet absorption in the absence of detectable analytical wavelengths (Figure 6 (c)), it is convenient to characterize the EHS structure by fluorescence spectra (Figure 6 (d)). The photophysical properties of humic acids containing numerous closed cycles, variations of substitutes, and delocalized $\pi$-bonds have undergone some changes - the intensity of green fluorescence in the $560 \mathrm{~nm}$ region significantly increased.

\subsection{Static and Dynamic Light Scattering (SLS/DLS)}

The measurement of light scattering of the polyelectrolyte samples allows the estimation of molecular and supramolecular parameters that are important for their identification and characterization. The joint use of the DLS and SLS techniques makes it more efficient to determine particle sizes, aggregation phenomena, interparticle interactions, investigation of the structure and relaxation dynamics of complex fluids when the molecular association/dissociation occurs simultaneously [44-45] (Figure 7).

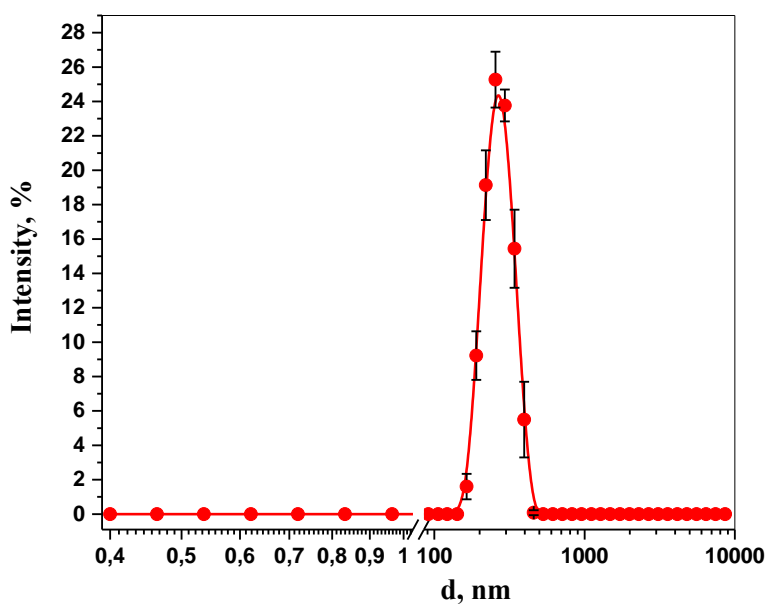

(a)

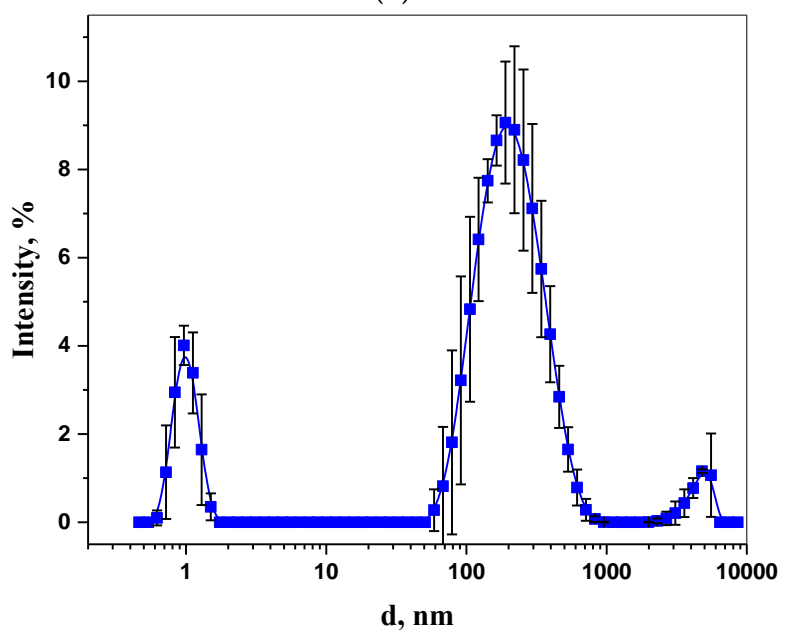

(c)

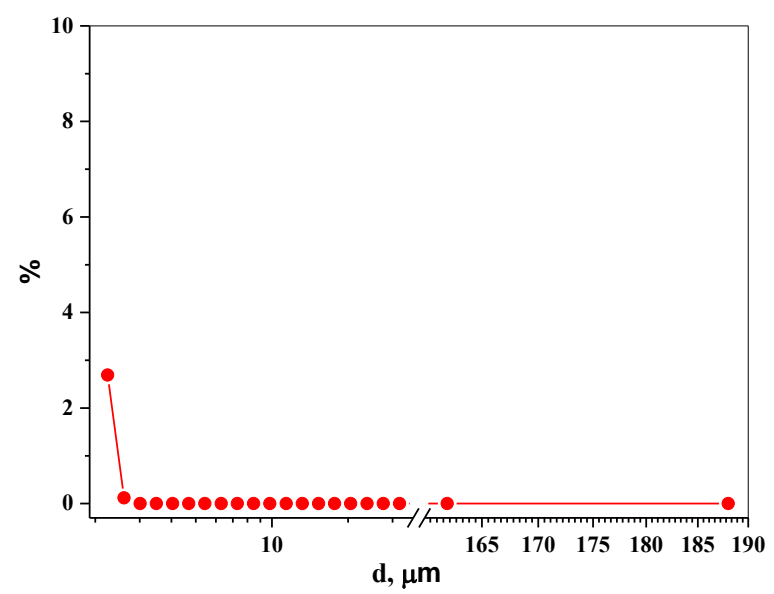

(b)

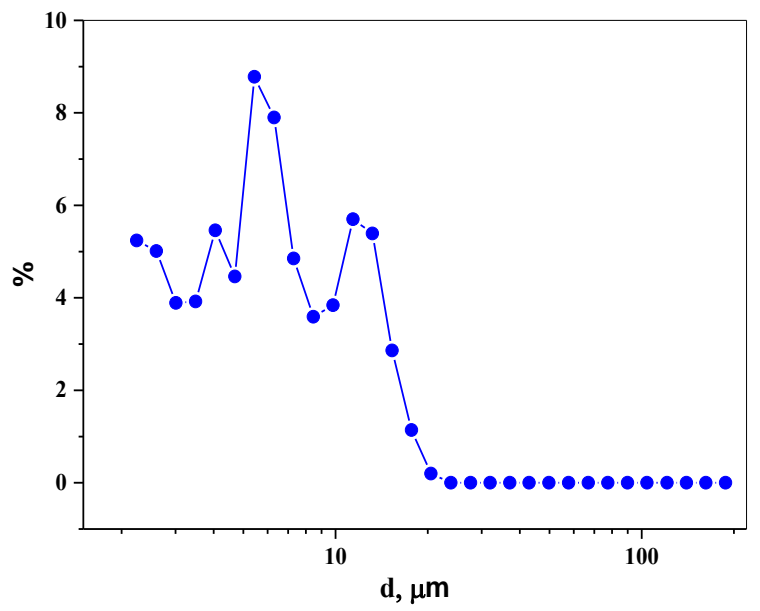

(d)

Figure 7. Particle size distribution based on dynamic and static light scattering data: (a), (b) EHS; (c), (d) FA.

The DLS technique in a dilution solution EHS 1:104 detected particles in the monomeric state, occupying the region from $130 \mathrm{~nm}$ to $400 \mathrm{~nm}$ with a maximum at 200 $\mathrm{nm}$. According to the SLS technique, there are no particles in the size region from 1 
to $200 \mu \mathrm{m}$. An aqueous dilution (1:2) sample of FA shows a bimodal distribution with peaks at $1 \mathrm{~nm}$ and $180 \mathrm{~nm}$ according to DLS data. The volume fraction of micron aggregates in the FA sample is distributed over three size groups: $4 \mu \mathrm{m}, 9 \mu \mathrm{m}$, $12 \mu \mathrm{m}$. Thus, the EHS and FA nanoparticles found in the investigated samples determine their biochemical and physical properties, which predetermine the transfer through cell membranes by different paths solely because of their size. This quality can be used for the delivery of drugs and nucleic acids into cells [46-48].

Further experimental analysis showed the existence of a relationship between the particle size, their biological activity and the efficiency of internalization of nanoparticles by EHS and FA cells.

\subsection{Biological activity study}

\subsubsection{Spirotox-test}

The investigation of individual and combined biological activity in accordance with the Arrhenius model of temperature kinetics were carried out using the test culture Spirostomum ambigua [49]. The description of the mechanisms of ligand-receptor interaction in the study of the biological activity of substances makes it possible to quantitatively evaluate the biological response of a cellular biosensor to the effect of a toxicant [50].

The existence of a transition state in the process of ligand-induced death of the test object means that the process of cell death occurs with energy consumption. However, the Spirotox experiment using EHS and FA samples demonstrated the absence of toxicity and a significant lifespan of the cellular biosensor in these media. We assume that the reason for the observed phenomenon lies in the unique ability of humified substances to perceive the effects produced without changing properties for an indefinitely long period, showing the effect of the assimilation potential (AP) [51]. To assess the biological activity of EHS, which showed the AP effect, we selected an object of a drug substance with antibacterial action - moxifloxacin hydrochloride $(\mathrm{Mxf} \mathrm{HCl})$ - belonging to the fluoroquinolone group. It was found that ligand-induced cell transitions are linearized in Arrhenius coordinates:

$$
\ln k=\ln A-\frac{E_{a}}{R} \cdot \frac{1}{T},
$$

where $\mathrm{k}$ is the rate constant, Ea is the activation energy, $\mathrm{R}$ is the gas constant, $\mathrm{A}$ is the preexponential factor, and $\mathrm{T}$ is the temperature.

In semilogarithmic coordinates, the tangent of the straight-line slope $\ln \left(1 / \mathrm{t}_{\mathrm{L}}\right)=\mathrm{F}(1 / \mathrm{T})$ to the abscissa axis is $\mathrm{E}_{\mathrm{a}} / \mathrm{R}$. The values of observed activation energy (obsEa) for the test compounds have been found, using Arrhenius coordinates (Table 2).

Table 2. The calculated obsEa values of ligand-induced S. ambigua death process in water and EHS solutions of $\mathrm{Mxf} \mathrm{HCl} ; \mathrm{n}=5$.

\begin{tabular}{cc}
\hline Sample solution & ${ }^{\text {obsEa }} \pm$ SD, J mol$^{-1}$ \\
\hline Water solution with $0,094 \% \mathrm{Mxf} \mathrm{HCl}$ & $157 \pm 2,5$ \\
EHS solution with 0,160\% Mxf HCl & $196 \pm 7$ \\
\hline
\end{tabular}

The largest value of activation energy, as well as the increase of Sp. ambigua lifetime by about 1,25 times at the same temperature for EHS solution of $\mathrm{Mxf} \mathrm{HCl}$ compared to water solution of $\mathrm{Mxf} \mathrm{HCl}$, indicates higher biological activity of this object.

2.5.2. Determination of the cytotoxic effect of the study objects on the cell culture Vero E6

The cytotoxic effect was determined by incubation of the investigated humic acids of various concentrations with Vero-E6 cells for $96 \mathrm{~h}$ using the MTS vital dye and visual assessment of the cell monolayer. Based on the data obtained in the investigation of the 
cytotoxic effect on the culture of Vero-E6 cells using the MTS vital dye, there were constructed analytical curves, from which the $\mathrm{CC}_{50}$ was determined for EHS and FA. The concentration that reduced the optical density value by $50 \%$ compared to the control cells was $3.19 \mu \mathrm{g} / \mathrm{ml}$ (EHS series 1), $3.13 \mu \mathrm{g} / \mathrm{ml}$ (EHS series 2) and $3.22 \mu \mathrm{g} / \mathrm{ml}$ (EHS series 3). The FA concentration, which reduced the optical density by $50 \%$ compared to the control cells, could not be determined, since it was higher than the 1:2 dilution (Figure 8).

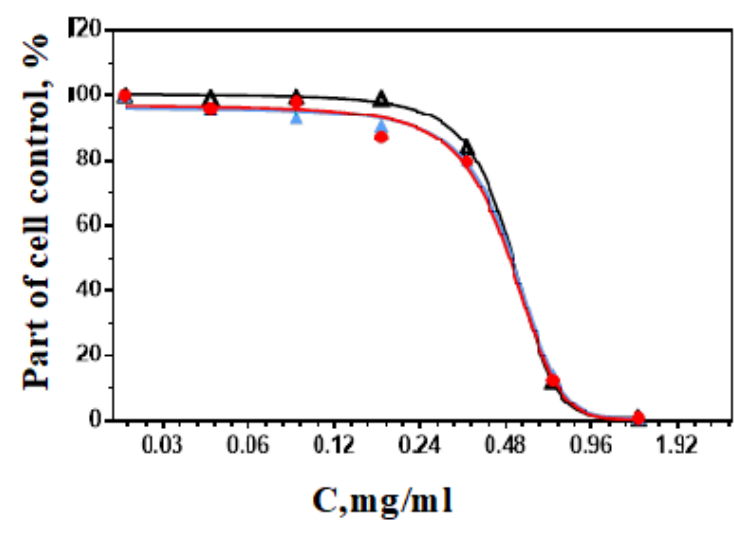

(a)

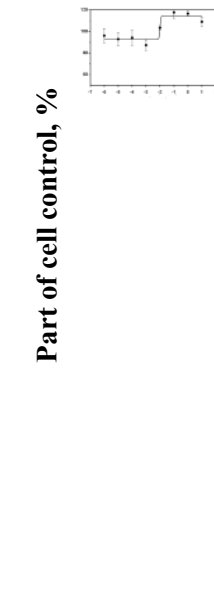

$\mathrm{C}, \mathbf{m g} / \mathbf{m l}$

(b)

Figure 8. Determination of the cytotoxic effect $96 \mathrm{~h}$ after the EHA and FA addition to the transplanted kidney cell line of the African green monkey Vero-E6 (using the MTS vital dye): (a) Humic acid extract, EHS 1 black - CC 50=3,19 mg/ml, EHS 2 red $-\mathrm{CC}_{50}=3,13 \mathrm{mg} / \mathrm{ml}$, EH S 3 blue $-\mathrm{CC}_{50}=3,22 \mathrm{mg} / \mathrm{m}$.; (b) Fulvic acid $\mathrm{CC}_{50}=2,0 \mathrm{mg} / \mathrm{ml}$.

Table 3 shows the results of the investigations carried out to study the virucidal and therapeutic-prophylactic activity of three series of the extract of humic acids in concentrations non-toxic for the culture of Vero E6 cells.

Table 3. The effect of EHS on the replication of SARS-CoV-2 in the culture of Vero E6 cells.

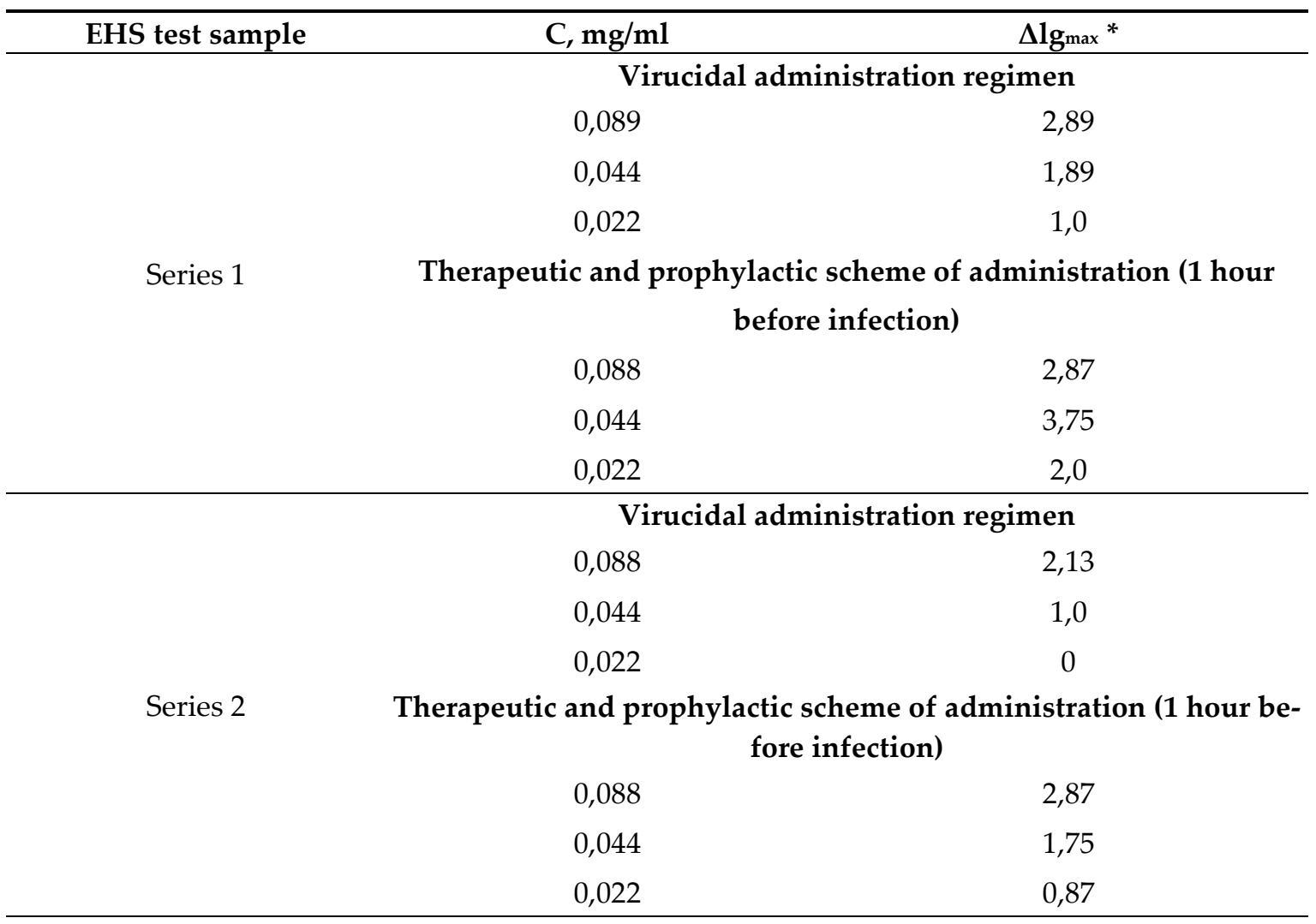




\begin{tabular}{cc}
0,088 & 3,75 \\
0,044 & 1,75 \\
0,022 & 0 \\
Therapeutic and prophylactic scheme of administration (1 hour be- \\
fore infection) \\
0,088 & 2,87 \\
0,044 & 2,75 \\
0,022 & 1,75 \\
\hline
\end{tabular}

* Reduction of the virus infectivity infectious titer with the drug compared with the control virus expressed in decimal logarithms

Thus, in the investigation of the virucidal activity at a concentration of $0.022 \mathrm{mg} / \mathrm{ml}$, EHS2 and EHS3 did not have an inhibitory effect on the reproduction of SARS-CoV-2, EHS1 showed a weak inhibitory effect. Moreover, (EHS2) showed the weakest inhibitory effect in the study of the virucidal activity at a concentration of $0.044 \mathrm{mg} / \mathrm{ml}$ and in the study of the antiviral activity according to the therapeutic-prophylactic model scheme at a concentration of $0.022 \mathrm{mg} / \mathrm{ml}$, suppressing the reproduction of the SARS-CoV-2 virus by $\leq 1.0 \mathrm{lg}$.

Based on the primary data obtained for EHS1, EHS2, EHS3, there were constructed analytical curves, from which 50\% inhibitory concentration was determined (IC50). The results for virucidal and therapeutic-prophylactic schemes of injecting the extract of humic substances are shown in Figure 9.

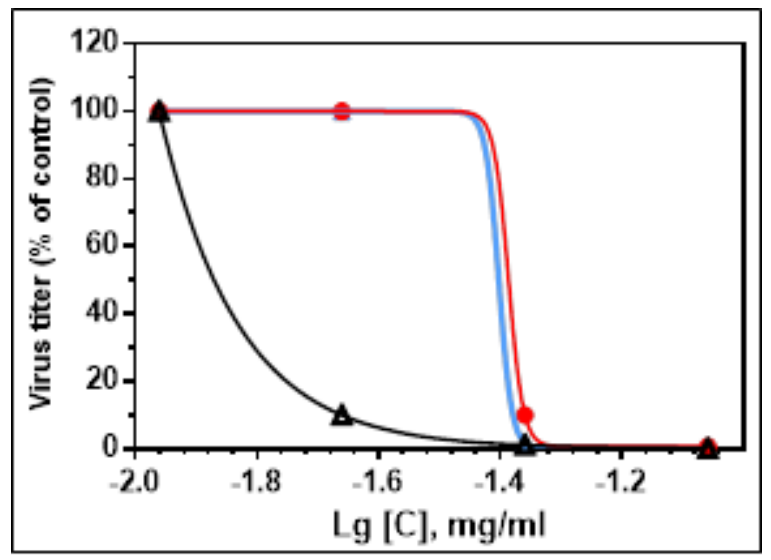

(a)

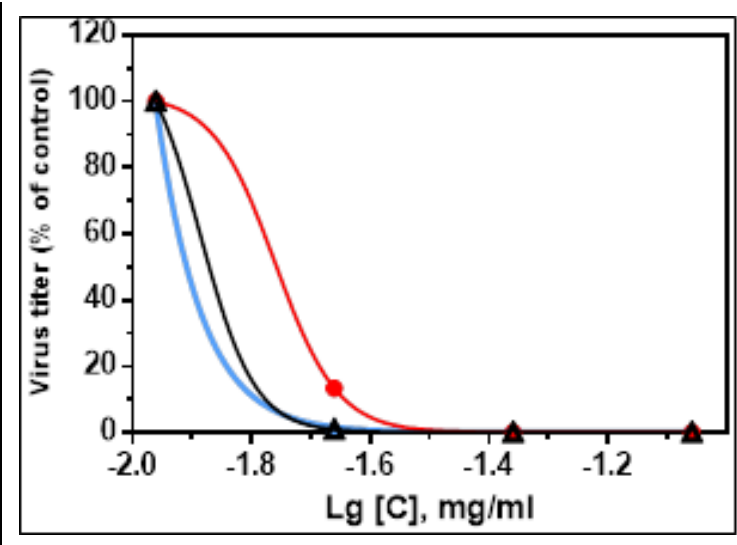

(b)

Figure 9. Determination of the IC 50 of humic acid extracts against SARS-CoV-2 in Vero E6 cell culture: (a) Humic acid extract with a virucidal scheme, EHS 1 black - IC ${ }_{50}=0,002 \mathrm{mg} / \mathrm{ml}$, EHS 2 red - IC $50=0,041 \mathrm{mg} / \mathrm{ml}$, EHS 3 blue $-\mathrm{IC}_{50}=0,039 \mathrm{mg} / \mathrm{mL}$; (b) Humic acid extract with a therapeutic and prophylactic scheme, EHS1 black - IC $50=0,013 \mathrm{mg} / \mathrm{ml}$, EHS2 red - IC ${ }_{50}=0,017 \mathrm{mg} / \mathrm{ml}$, EHS3 blue $\mathrm{IC}_{50}=0,007 \mathrm{mg} / \mathrm{m}$.

In the therapeutic-prophylactic model scheme of injection, FA inhibited the replication of SARS-CoV-2 in Vero E6 cell culture at concentrations of $0.2 \mathrm{mg} / \mathrm{ml}, 0.1 \mathrm{mg} / \mathrm{ml}$, reducing the virus infectivity titer by 1.75-1.0 1g TCID 50 (tissue culture infectious dose), respectively. Based on the primary data, there was constructed an analytical curve, from which $50 \%$ inhibitory concentration (IC 50 ) was determined (Figure 10 ): 


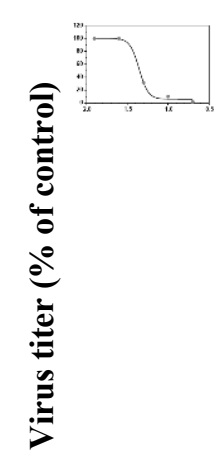

$\lg \mathrm{C}, \mathrm{mg} / \mathrm{ml}$

Figure 10. Determination of the $\mathrm{IC}_{50}$ of the drug Fulvic against SARS-CoV-2 in Vero E6 cell culture.

Table 5 shows the results of the cytotoxic and antiviral activities of EHS and FA against the SARS-CoV-2 virus in the Vero E6 cell culture.

Table 5. Consolidated data on cytotoxic and antiviral activity EHS and FA.

\begin{tabular}{|c|c|c|c|c|}
\hline \multirow{3}{*}{ Test sample } & \multirow{3}{*}{$\mathrm{CC}_{50,} \mathrm{mg} / \mathrm{ml}$} & \multirow{2}{*}{\multicolumn{3}{|c|}{$\begin{array}{l}\text { Antiviral activities against the SARS- } \\
\qquad \text { CoV-2 virus }\end{array}$}} \\
\hline & & & & \\
\hline & & $\Delta \lg _{\max }$ & $\mathrm{IC}_{50}, \mathrm{mg} / \mathrm{ml}$ & SI \\
\hline \multicolumn{5}{|c|}{ Virucidal administration regimen } \\
\hline EHS 1 & 3,19 & 2,89 & 0,002 & 1593,5 \\
\hline EHS 2 & 3,13 & 2,13 & 0,041 & 76,3 \\
\hline EHS 3 & 3,22 & 3,75 & 0,039 & 82,4 \\
\hline \multicolumn{5}{|c|}{ Treatment and prevention model scheme } \\
\hline EHS 1 & 3,19 & 3,75 & 0,013 & 245 \\
\hline EHS 2 & 3,13 & 2,87 & 0,017 & 184 \\
\hline EHS 3 & 3,22 & 2,87 & 0,007 & 459,3 \\
\hline FA & 2 & 1,75 & 0,044 & 45,5 \\
\hline
\end{tabular}

\section{Discussion}

The humus acids are high molecular weight polyelectrolytes, the structural units of which are represented by aromatic condensed systems with side chains and heterocycles [52]. The physico-chemical properties of the humus acids, including humic, fulvic, and other acids extracted by alkali solutions were investigated with the involvement of a significant fleet of equipment [53]. However, the properties of the humic and fulvic acids can vary depending on the medium of their formation - humification [54]. This is the reason for many publications about the properties of the humus acids. All this leads to an unambiguous decision on the need for standardization and development of quality control methods for the components of the humus acids.

This problem is especially relevant in connection with the data appearing in the literature on the significant biological activity of the components of humus acids - antitumor, antibacterial, antifungal, antiviral [55-57]. Due to the massive spread of new strains of the coronavirus infection, the development of drugs that suppress the replication of the SARS-CoV-2 virus is urgent [58].

The results of this study of the antiviral activity showed that the study objects in the culture of Vero-E6 cells, in doses non-toxic to cells, suppress the reproduction of the SARSCoV-2 virus both in the study of the virucidal effect and in the study of the antiviral activity according to the therapeutic-prophylactic model scheme of injection. The difference in activity of different EHS series can be related to its heterogeneity and sophisticated complex composition (see Figure 1). According to the criteria for evaluating the antiviral 
effect of drugs in vitro, compounds, in which the decrease in the virus titer in concentrations non-toxic for the cell culture is at least 1.5-2.0 $\mathrm{lg}$ and $\mathrm{SI} \geq 8$, exhibit pronounced activity.

The properties and widespread medical application of nanoparticles to enhance contrast in magnetic resonance imaging, in immunoassays and drug delivery are well known from the literature [59]. The internalization of nanoparticles and their absorption by cells, depending on the size, have been shown [60]

The results of our research have shown that the composition of the components of humus acids includes occluded metal nanoparticles in addition to the organic structure of nonstoichiometric composition and an irregular heterogeneous structure with many functional groups. Apparently, their presence determines their properties as nanocontainers [61]. Objects that are not characterized by nanosized particles completely lose the described properties [62]. Our studies emphasize that the consideration of the humus acids and their components - humic and fulvic acids from the standpoint of metal-organic nanosized objects can explain the detected virucidal activity, as well as become a potential object for creating a promising standardized drug.

\section{Materials and Methods}

\subsection{Materials}

\subsubsection{EHS and FA Samples}

A natural complex of humic-fulvic acids isolated from low-lying peat, sapropel and some varieties of brown coal (leonardite) using the technology of the VimaVita Company (Sistema-BioTechnologii LLC, RF). The HS concentrate containing humic acids (HA), himatomelanic acids (HMC), fulvic acids (FA), humus acids (HFA) and structural analogs of humic substances was obtained by the method of oxidative-hydrolytic destruction of lignin-containing raw materials (solid-phase fermentation) with subsequent purification [63]. As a result of high-intensity acoustic cleaning, a concentrated viscous colloidal disperse system of humic substances of dark brown color was obtained for research. $(\mathrm{pH}=7.98 \pm 0.1)$.

Fulvic acid extract (Terra Aquatica, France) in the form of a liquid, transparent solution of brown color, obtained by extraction from a special type of brown coal leonardite $(\mathrm{pH}=5,77 \pm 0,1)$.

To study the physico-chemical properties of HS and FA, aqueous solutions of the initial concentrate were prepared. All solutions of humic substances fractions were stored at $+4^{\circ} \mathrm{C}$.

4.1.2. Cell Culture. The study was carried out on a finite kidney cell line of the African green monkey (Chlorocebus aethiops) Vero-E6. MEM medium with glutamine (Capricorn Scientific $\mathrm{GmbH}$, Germany) containing $10 \%$ and $2 \%$ fetal calf serum (Biosera, USA) respectively and gentamicin $(50 \mu \mathrm{g} / \mathrm{ml}$ ) (Capricorn Scientific $\mathrm{GmbH}$, Germany) was used as a growth medium (GM) for growing cells and as a supporting medium (SM) for setting up a reaction. Vero-E6 cells were cultured in 96-well plates in a volume of $100 \mu \mathrm{l}$ of GM for $24 \mathrm{~h}$ at $37^{\circ} \mathrm{C}$ in an atmosphere with $5 \% \mathrm{CO}_{2}$. The inoculation dose was 18,000 cells/well.

4.1.3. Virus. The study used the SARS-CoV-2 human coronavirus, passage 3, with infectivity of $10^{7.5}$ TCID 50/ml. Strain description: hCoV-19/Russia/Moscow-PMVL-12/2020 (EPI_ISL_572398) GISAD: PMVL-12. Booking reference EPL_ISL_572398.

4.1.4. Study Design. The study of the antiviral activity of the study objects was carried out in accordance with the requirements of the Pharmacological State Committee of the Russian Federation for the experimental (preclinical) study of new pharmacological substances. The study included: determination and assessment of the cytotoxic effect of the study objects on the morphology and viability of Vero-E6 cells, as well as the study of the antiviral activity against SARS-CoV-2.

4.2. Determination of the cytotoxic effect of the study objects on the cell culture Vero - E6.

Multiple dilutions of the study objects were prepared in plates by titration in 7-8 wells with a step of $\times 2$ on GM medium. The solutions of the study objects were transferred in $200.0 \mu \mathrm{l}$ into the wells of the test plates with cells. Each point was tested in 4 parallel 
rows of plate wells. $200 \mu \mathrm{l}$ of SM without study objects was used as a control of the state of the cell culture. The plates were incubated for 96 hours at $37 \pm 0.5^{\circ} \mathrm{C}$ in atmosphere with $5 \% \mathrm{CO}_{2}$. The state of the cell monolayer was visually assessed to identify destructive changes and changes in the morphology of the cell monolayer. After 96 hours, the culture medium was removed and $100 \mu \mathrm{l}$ of GM and $20 \mu \mathrm{l}$ of vital dye (MTS) (CellTiter 96® AQueous One Solution Cell Proliferation Assay, Promega, G3582) were added to each well. After incubation for 3 hours at $37 \pm 0.5^{\circ} \mathrm{C}$, the results were recorded on a BIO-RAD reader at a wavelength of $490 \mathrm{~nm}$, the reference wave was $630 \mathrm{~nm}$. The concentration of the test substance, which reduces the optical density value by $50 \%$ compared to the control cells, was taken as the $50 \%$ cytotoxic dose $\left(\mathrm{CC}_{50}\right)$.

4.3. In Vitro Study of the Antiviral Activity of EHS and FA.

At the second stage of the study, the virucidal activity against SARS-CoV-2 of three series of the extract of humic substances was studied, as well as their antiviral activity according to a therapeutic-prophylactic model scheme. Each series of the drug was tested at three concentrations. The antiviral activity of the Fulvic drug was studied using a therapeutic-prophylactic model scheme at 4 concentrations. The selection of concentrations for the studies of antiviral activity was carried out on the basis of the results of the study of cytotoxic action within the range of concentrations that are not toxic to cells (i.e., lower than the $\mathrm{CC}_{50}$ value).

When studying the virucidal effect, the selected dilutions of the drugs (according to $\mathrm{CC}_{50}$ ) were mixed with dilutions of the virus (from $10^{-1}$ to $10^{-7}$ ) in equal volumes of $100 \mu \mathrm{l}$ and incubated for 1 hour at $37 \pm 0.5^{\circ} \mathrm{C}$ in atmosphere with $5 \% \mathrm{CO}_{2}$ and transferred to a plate with a monolayer of washed cells. To study the antiviral activity according to the therapeutic-prophylactic model scheme, working dilutions of the study objects were added to the cells 1 hour before infection with the virus and incubated at $37 \pm 0.5^{\circ} \mathrm{C}$ in an atmosphere of $5 \% \mathrm{CO}_{2}$.

As a control, we used SARS-CoV-2 virus dilutions from $10^{-1}$ to $10^{-7}$ without adding study objects. Each drug concentration was tested in four parallel rows of plate wells. The plates were incubated for 96 hours at $37 \pm 0.5^{\circ} \mathrm{C}$ in atmosphere with $5 \% \mathrm{CO}_{2}$. The antiviral activity was assessed visually under a microscope 96 hours after infection by inhibition of the cytopathic effect (CPE) of the virus on the cells. The result was assessed by $\Delta \lg _{\max }-$ the maximum decrease in the value of the infectious viral dose in the experiment in comparison with the control expressed in decimal logarithms.

\subsection{Statistical Data Processing}

The calculation of the values of 50\% cytotoxic concentration $\left(\mathrm{CC}_{50}\right)$ and $50 \%$ effective concentration ( $\mathrm{IC}_{50}$ ) was performed by methods generally accepted for biological research using the Microsoft Excel 5.0 and GraphPad Prism 6.01 software package. The 4-parameter equation of the logistic curve (menu items "Nonlinear regression" - "Sigmoidal doseresponse (variable slope)") was adopted as a working model for the $\mathrm{CC}_{50}$ analysis. The 4parameter equation of the logistic curve (menu items "Nonlinear regression" - "log (inhibitor) vs. response (variable slope)") was adopted for the analysis of $\mathrm{IC}_{50}$. Based on the data obtained, SI was calculated using the equation: $S I=C C_{50} / I C_{50}$.

\subsection{Loss on drying (LOD)}

The determination of the mass loss of extract of humic substances and liquid fulvic acid on drying was carried out according to the requirements [27]. For this purpose, the accurately measured weight of the tested liquid substance, pre-dried and brought to constant weight, was placed in an evaporating dish (porcelain). The drying was carried out in at $105 \pm 5^{\circ} \mathrm{C}$ for 6 hours in a drying oven BINDER FD (Germany) that provides uniform heat treatment of the entire usable chamber volume [65]. The weight of the sample dish was determined and recorded every hour by removing the dish from the oven and allowing it to cool at room temperature in a desiccator for 30 minutes. The loss on drying (\%) was calculated according to the Table 6 and following equation:

$$
\mathrm{W}=\frac{m_{2}-m_{3}}{m_{2}-m_{1}} \cdot 100 \%
$$


were $\mathrm{m}_{1}$ is the weight of the measuring cup brought to a constant weight (g); $\mathrm{m}_{2}$ is the weight of the measuring cup containing the tested sample before drying (g); $\mathrm{m}_{3}$ is the weight of the measuring cup containing the tested sample after drying (g).

Table 6. Determination of weight loss on drying the samples of the extract of humic substances and fulvic acid.

\begin{tabular}{ccccc}
\hline \multicolumn{5}{c}{ Extract humic substances (EHS) } \\
\hline $\mathbf{t}, \mathbf{h}$ & $\mathbf{m}_{1}, \mathbf{g}$ & $\mathbf{m}_{2}, \mathbf{g}$ & $\mathbf{m}$ (tested liquid substance) $\mathbf{g}$ & $\begin{array}{c}\text { Loss on drying } \\
\text { (LOD), } \%\end{array}$ \\
\hline 0 & 118,6004 & 127,2238 & 8,6234 & \\
1 & & 119,2702 & 0,6698 & \\
2 & & 119,2473 & 0,6469 & \\
3 & 119,2411 & 0,6407 & \\
& $\mathbf{m}_{3,} \mathbf{g}$ & & \\
4 & 119,2362 & 0,6358 & \\
5 & & 119,2362 & 0,6358 & \\
6 & & 119,2362 & 0,6358 & \\
\end{tabular}

92,63

\begin{tabular}{ccccc}
\hline \multicolumn{5}{c}{ Fulvic acid (FA) } \\
\hline $\mathbf{t}, \mathbf{h}$ & $\mathbf{m}_{1}, \mathbf{g}$ & $\mathbf{m}_{2}, \mathbf{g}$ & $\mathbf{m}$ (tested liquid substance) $\mathbf{g}$ & $\begin{array}{c}\text { Loss on drying } \\
\text { (LOD), } \%\end{array}$ \\
\hline 0 & 115,3210 & 120,1194 & 4,7984 & \\
1 & & 115,3398 & 0,0188 & \\
2 & & 115,3391 & 0,0181 & \\
3 & 115,3387 & 0,0177 & \\
& & $\mathbf{m}_{3}, \mathbf{g}$ & & \\
4 & 115.3371 & 0,0161 & \\
5 & & 115.3371 & 0,0161 & \\
6 & 115.3371 & 0,0161 & \\
& & & & \\
\hline
\end{tabular}

The weight loss on drying test carried out in this manner allowed the determination of the EHS and FA content of non-volatile substances in the samples, as well as the weight loss on drying.

\subsection{Optical Microscopy (OM)}

Determination of the size, shape, and granulometric composition of the dry residue in the EHS and FA samples was carried out using a microscope with a special binocular attachment (Altami BIO 2, Russia) with magnification 10X (linear field of view $20 \mathrm{~mm}$ ). To do this, a sample of dry matter was distributed on a glass slide without adhesion of particles. The preliminary calibration was carried out using a micrometer object with a scale of $1 \mathrm{DIV}=0.01 \mathrm{~mm}$. The particles were observed in separate fields of view. The length was measured on microscopic images and the shape of the particles was determined using the Altami Studio 3.3 software [66].

\subsubsection{Digital Microscopy (DM)}

The surface structure of powdery substances obtained after drying the EHS and FA samples was investigated using a portable USB digital microscope LX200 (Levenhuk DTX 50, USA) to determine the size of objects from 1 to $50 \mu \mathrm{m}$ [67]. The microscope is equipped with a built-in digital 1.3 megapixel camera connected to a computer. The advantage of the digital microscope is the express diagnostics of large sample areas without sample 
preparation. The analysis of the structure, relief and defects of the layers adjacent to the surface allowed us to identify the objects under study.

\subsection{X-ray Fluorescence (XRF)}

An energy dispersive X-ray fluorescence spectrometer (EDX-7000P, Shimadzu Europa $\mathrm{GmbH}$ ) based on a silicon drift detector with thermoelectric cooling equipped with the PCEDX-Navi software package was used to carry out the nondestructive elemental composition of powder and liquid EHS and FA samples. The range of elements measured by the X-ray fluorescence method is from $11 \mathrm{Na}$ to $92 \mathrm{U}$; the X-ray generator is a tube with Rh-anode, current 1-1,000 $\mu \mathrm{A}$; the irradiated area controlled by the collimator was $10 \mathrm{~mm}$ [68]. Pelleted powder or liquid sample of EHS and FA was placed in a closed cuvette covered with a mylar (lavsan) film in air atmosphere and placed exactly in the center of the instrument window. The intensity of the secondary fluorescent radiation was measured to determine the elemental composition of the sample. The study time was 50 seconds for each element (group).

\subsection{Fourier-Transform IR Spectroscopy}

To obtain and analyze the vibrational spectra of the EHS and FA samples in the spectral range from 4,000 to $750 \mathrm{~cm}^{-1}$, an IR Fourier spectrophotometer (Agilent Cary 630, USA) with a transmission attachment was used [69]. Sample preparation - solid residue after drying - for spectrum recording was carried out in accordance with the requirements[70]. For this, about $1 \mathrm{mg}$ of dry residue was triturated with $400 \mathrm{mg}$ of carefully ground and dried potassium bromide until uniform state and compressed for 3-5 minutes to obtain a disk diameter of about $13 \mathrm{~mm}$ to have a spectrum of a suitable intensity.

\subsection{Fluorescence and UV-Spectroscopy}

To obtain the fluorescence spectra of a series of dilutions of the EHS and FA samples, we used an AGILENT Cary Eclipse spectrofluorimeter (USA) with two ultrafast scanning monochromators. The excitation wavelength was $280 \mathrm{~nm}$. The fluorescence spectra in the range from 300 to $800 \mathrm{~nm}$ with the maxima of violet and green fluorescence was studied.

The absorption spectrum of an aqueous dilution blank (1:100) of FA was obtained in the range from $200 \mathrm{~nm}$ to $350 \mathrm{~nm}$ using AGILENT Cary 60 equipment (USA).

\subsection{Determination of Particle Sizes of Dispersed Systems}

To determine the particle size of dispersed systems, the methods of static and dynamic light scattering of aqueous dilutions of EHS and FA were used.

\subsubsection{Static and Dynamic Light Scattering (SLS/DLS)}

The particle size analysis (volumetric distribution on an ensemble of particles by size/size spectra) was recorded by static light scattering (Low-angle laser light scattering, LALLS) using a MasterSizer 3600 Ec small-angle laser dispersion meter (Malvern, UK) [71-72]. The optical module of the equipment used makes it possible to determine the size of the dispersed phase particles in the range from $1 \mu \mathrm{m}$ to $180 \mu \mathrm{m}$ based on the measurement of the angular dependence of the intensity of the scattered laser light passing through the dispersed sample [73]. For the granulometric analysis of the samples under investigation, there were used dilutions of EHS and FA in water 1:1000 and 1:2, respectively.

A Zetasizer Nano ZSP (Malvern, UK) based on dynamic light scattering (DLS) was used to measure the size of nanoparticles in the EHS and FA samples from $0.1 \mathrm{~nm}$ to 10,000 $\mathrm{nm}$. DLS technology measures particle diffusion due to Brownian motion with its subsequent transformation into size according to the Stokes-Einstein equation [74]:

$$
D=\frac{k_{B} T}{6 \pi \eta r^{\prime}}
$$


were $\mathrm{D}$ is the diffusion coefficient, $\mathrm{k}_{\mathrm{B}}$ is the Boltzmann constant, $\mathrm{T}$ is an absolute temperature, $\eta$ is the liquid viscosity, $r$ is the particle radius.

The dispersion analysis was performed using a Malvern ZetaSizer Nano ZS series analyzer.

\subsection{Spirotox Method}

The study of the biological activity of aqueous dilutions of EHS in the presence of fluoroquinolone supplement was carried out using the cell culture Spirostomum ambigua [75-76]. The mechanism of ligand-receptor interaction includes the stage of interaction of the xenobiotic with the cell, the disintegration of the intermediate complex, accompanied by a change in the concentration of the cellular biosensor due to conformational changes in the receptor, degradation, synthesis of new receptors and the formation of the intermediate state C. Ln (Figure 12).

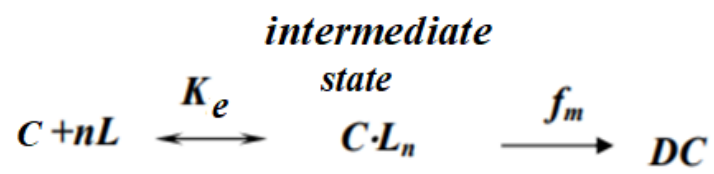

Figure 12. Kinetic scheme of ligand-receptor interaction S. ambigua with toxicant: C-cell, L-ligand, n-stoichiometric coefficient, C. Ln - intermediate state (cell after interaction with the ligand), Ke is the equilibrium constant fast stage, $\mathrm{f}_{\mathrm{m}}$ is the rate constant of the cell transition to the dead state, DC is a dead cell [77].

\section{Conclusions}

A comprehensive study of the properties of humus acids drugs - an extract of humic substances and fulvic acid - was carried out using gravimetric, optical and biological methods. The dry matter content of the samples differs by a factor of 22, the weight loss due to volatiles on drying is $92.63 \%, 63$ and $99.66 \%$ for EHS and FA, respectively. The Xray fluorescence analysis showed a high content of $\mathrm{Fe}$ and $\mathrm{Cu}$ in the samples. The fluorescence intensity and the number of determined elements increase significantly when the samples are dried. The elemental composition indicates the possible formation of watersoluble $\mathrm{Fe} / \mathrm{Cu}-\mathrm{HS}$ complexes, which are necessary in nature for plant nutrition. This can explain the absence of toxicity of the humus acids when the cell model is exposed to the Spirotox method. Nanoparticles detected by the DLS technique in the range from $1 \mathrm{~nm}$ to $200 \mathrm{~nm}$ in the HS samples can have a structure of lipid-like objects with occluded iron penetrating through cell membranes into an organic matrix, which was demonstrated by the suppression of the SARS-CoV-2 reproduction in the Vero-E6 cell culture. The IR spectroscopy has demonstrated the appearance of bands characteristic of Fe nanoparticles. The structure of chromone (benzo- $\gamma$-pyrone) in samples of humus acids has also been proven, which is a powerful fluorophore and chromophore according to FL and UV spectroscopy methods. Thus, samples of humate chromone can be of important interest and be promising candidates for practical application in the fields of biomedicine after quality and biological activity tests.

Author Contributions: Conceptualization, A.V.S., T.V.G. and T.V.P.; methodology, E.V.U., A.V.S.; investigation, I.V.K., V.V.L., I.T.F., O.V.E.; validation, V.F.L., T.M.G.; data curation, A.V.S., T.V.G. and E.V.U.; formal analysis, I.V.K; writing - original draft preparation, E.V.U.; writing - review and editing, A.V.S., T.V.G. and T.V.P. All the authors discussed the results and commented on the manuscript.

Funding: This research received no external funding.

Institutional Review Board Statement: Not applicable.

Informed Consent Statement: Not applicable. 
Acknowledgments: This paper was supported by the RUDN University Strategic Academic Leadership Program

Conflicts of Interest: The authors declare that there are no conflicts of interest regarding the publication of this paper.

Sample Availability: Samples of the compounds are available from the authors.

\section{Abbreviations}

\begin{tabular}{|c|c|}
\hline COVID-19 & Corona Virus Disease 2019 \\
\hline $\mathrm{CC}_{50}$ & half maximal cytotoxic concentration \\
\hline CPA & cytopathic action \\
\hline DLS & dynamic light scattering \\
\hline EHS & extract humic substances \\
\hline obs $\mathrm{Ea}_{\mathrm{a}}$ & obseved activation energy \\
\hline ESIPT & excited state intramolecular proton transfer \\
\hline EDXRF & energy dispersive X-ray fluorescence \\
\hline FA & fluvic acids \\
\hline $\mathrm{FRO}$ & ferric chelate reductase \\
\hline GE & growth environment \\
\hline HA & humic acids \\
\hline HS & humic substances \\
\hline HMA & hymatomelanic acid \\
\hline $\mathrm{IC}_{50}$ & half maximal inhibitory concentration \\
\hline IHS & insoluble HS \\
\hline HIV-1 & human immunodeficiency virus \\
\hline HSV-1 & simplex virus-1 \\
\hline IRT & iron transporter \\
\hline IR & infra-red \\
\hline MEM & minimum essential medium (alpha 1X) \\
\hline MTS & vital dye (1-solution methyl thiazolyl tetrazolium) \\
\hline SE & supportive environment \\
\hline SI & selectivity index \\
\hline $\begin{array}{l}\text { SARS-CoV-2 } \\
\text { SLS }\end{array}$ & $\begin{array}{l}\text { severe acute respiratory syndrome-related coronavirus } 2 \\
\text { static light scattering }\end{array}$ \\
\hline Spirotox test & Spirostomum Ambiguum Acute Toxicity Test \\
\hline TBEV & tick-borne encephalitis virus \\
\hline TCID50 & $50 \%$ tissue culture infectious dose \\
\hline WEHS & water extractable humic substances \\
\hline Vero-E6 & $\begin{array}{l}\text { cell culture derived from epithelial buds of African green } \\
\text { monkey and transfected with a viral gene }\end{array}$ \\
\hline
\end{tabular}

\section{References}

1. International Humic Substance Society. Available online: https://humic-substances.org.

2. Wei, X.; Yang, Y.; Shen, Y.; Chen, Z.; Dong, Y.; Wu, F.; Zhan, L. Effects of Litterfall on the Accumulation of Extracted Soil Humic Substances in Subalpine Forests. Front Plant Sci 2020, 5, 254.

3. Li, Y.; Guo, L.X.; Zhou, Q.Z.; Chen, D.; Liu, J.Z.; Xu, X.M.; Wang, J.H. Characterization of Humic Substances in the Soils of Ophiocordyceps sinensis Habitats in the Sejila Mountain, Tibet: Implication for the Food Source of Thitarodes Larvae. Molecules 2019, 10, 246.

4. Meng, F.; Yuan, G.; Wei, J.; Bi, D.; Ok, Y.S.; Wang, H. Humic substances as a washing agent for Cd-contaminated soils. Chemosphere 2017, 81, 461-467.

5. Wnuk, E.; Waśko, A.; Walkiewicz, A.; Bartmiński, P.; Bejger, R.; Mielnik, L.; Bieganowski, A. The effects of humic substances on DNA isolation from soils. PeerJ 2020, 24, 9378. 
6. Shah, Z.H.; Rehman, H.M.; Akhtar, T.; Alsamadany, H.; Hamooh, B.T.; Mujtaba, T.; Daur, I.; Al Zahrani, Y.; Alzahrani, H.A.S.; Ali, S.; Yang, S.H.; Chung, G. Humic Substances: Determining Potential Molecular Regulatory Processes in Plants. Front Plant Sci 2018, 13, 263.

7. Zech, W.; Senesi, N.; Guggenberger, G.; Kaiser, K.; Lehmann, J.; Miano, T.M.; Miltner, A.; Schroth, G. Factors controlling humification and mineralization of soil organic matter in the tropics. Geoderma 1997, 79, 117-161.

8. Zhernov, Y.V.; Konstantinov, A.I.; Zherebker, A.; Nikolaev, E.; Orlov, A.; Savinykh, M.I.; Kornilaeva, G.V.; Karamov, E.V.; Perminova, I.V. Antiviral activity of natural humic substances and shilajit materials against HIV-1: Relation to structure. Environ Res 2021, 193, 110312.

9. Lomovskiy, I.; Bychkov, A.; Lomovsky, O.; Skripkina, T. Mechanochemical and Size Reduction Machines for Biorefining. Molecules 2020, 16, 5345.

10. Zanin, L.; Tomasi, N.; Cesco, S.; Varanini, Z.; Pinton, R. Humic Substances Contribute to Plant Iron Nutrition Acting as Chelators and Biostimulants. Front Plant Sci 2019,22, 675.

11. Stevenson, F. J. Humus chemistry : genesis, composition, reactions.; Publisher: New York, Wiley, 1982; pp. 443.

12. Kleinhempel, D. Ein Beitrag zur Theorie des Huminstoffzustandes. Arch. Agron. Soil Sci. 1970, 14, 3-14.

13. Tikhonov, V.V.; Orlov, D.S.; Lisovitskaia, O.V.; Zavgorodniaia, I.A.; Byzov, B.A.; Demin, V.V. Sorption of humic acids by bacteria. Mikrobiologiia 2013, 82, 691-7.

14. Esfahani, M.R.; Stretz, H.A.; Wells, M.J. Abiotic reversible self-assembly of fulvic and humic acid aggregates in low electrolytic conductivity solutions by dynamic light scattering and zeta potential investigation. Sci Total Environ 2015, 15, 8192.

15. Filella, M.; Buffle J.; Parthasarathy, N. Humic and fulvic compounds, 2nd ed.; Worsfold, P.; Townshend, A.; Poole, C.; Encyclopedia of Analytical Science, Elsevier, 2005; pp. 288-298.

16. Sanchez, J.C.; DiPasquale, A.G.; Mrse, A.A.; Trogler, W.C. Lewis acid-base interactions enhance explosives sensing in silacycle polymers. Anal Bioanal Chem 2009, 395, 387-92.

17. Avramenko, V.A.; Bratskaya, S.Y.; Yakushevich, A.S. Humic acids in brown coals from the southern Russian Far East: General characteristics and interactions with precious metals. Geochem. Int 2012, 50, 437-446.

18. Bratskaya, S.Y.; Volk, A.S.; Ivanov, V.V.; Ustinov, A.Y.; Barinov, N.N.; Avramenko, V.A. A new approach to precious metals recovery from brown coals: Correlation of recovery efficacy with the mechanism of metal-humic interactions. Geochim cosmochim ac 2009,73, 3301-3310.

19. Zhernov, Y.V.; Konstantinov, A.I.; Zherebker, A. Antiviral activity of natural humic substances and shilajit materials against HIV-1: Relation to structure. Environ Res 2021,193, 110312.

20. Lu, F.J.; Tseng, S.N.; Li, M.L.; Shih, S.R. In vitro anti-influenza virus activity of synthetic humate analogues derived from protocatechuic acid. Arch. Virol 2002, 147, 273-284.

21. Klocking, R.; Helbig, B.; Schotz, G.; Schacke, M.; Wutzler, P. Anti-HSV-1 activity of synthetic humic acid-like polymers derived from p-diphenolic starting com-pounds. Antivir. Chem. Chemother 2002, 13, 241-249.

22. Orlov, A.A.; Zherebker, A.; Eletskaya, A.A.; Chernikov, V.S.; Kozlovskaya, L.I.; Zhernov, Y.V.; Kostyukevich Y.; Palyulin, V.A.; Nikolaev, E.N.; Osolodkin, D.I.; Perminova, I.V. Examination of molecular space and feasible structures of bioactive components of humic substances by FTICR MS data mining in ChEMBL database. Sci. Rep 2019,9,12066.

23. Rensburg, C. E. J.; Dekker, A. S. J.; An in vitro investigation of the antimicrobial activity of oxifulvic acid. J Antimicrob Chemother 2000, 46, 853-854.

24. Wu, M.; Song, M.; Liu, M.; Jiang, C.; Li, Z. Fungicidal activities of soil humic/fulvic acids as related to their chemical structures in greenhouse vegetable fields with cultivation chronosequence. Sci Rep 2016, 6, 32858.

25. Zhernov, Y.V.; Kremb, S.; Helfer, M.; Schindler, M.; Harir, M.; Mueller, C.; Hertkorn, N.; Avvakumova, N.P.; Konstantinov, A.I.; Brack-Werner, R.; Sch mitt-Kopplin, P.; Perminova, I.V. Supramolecular combinations of humic polyanions as potent microbicides with polymodal anti-HIV-activities. New J. Chem 2017, 41, 212-224.

26. Hafez, M.; Popov, A. I.; Zelenkov, V.N.; Teplyakova, T.V.; Rashad, M. Humic substances as an environmental- friendly organic wastes potentially help as natural anti-virus to inhibit COVID-19. Science Archives 2020, 1, 53-60.

27. Ph. Eur. 10.0: EDQM, 2019; Volume 2.2.32, pp. 57-58.

28. Hunger, K.; Review of Progress in Coloration and Related Topics. The effect of crystal structure on colour application properties of organic pigments 2008, 29, 71-84.

29. Mondal, H.; Mondal, S.; Saha, K.; Roul, B.; Development of a Low-cost Smartphone-connected Digital Microscope. J Microsc Ultrastruct 2019, 29, 51-54.

30. Zanin, L.; Tomasi, N.; Cesco, S.; Varanini, Z.; Pinton, R.; Humic Substances Contribute to Plant Iron utrition Acting as Chelators and Biostimulants. Front Plant Sci 2019,10, 675.

31. Fuentes, M.; Olaetxea, M.; Baigorri, R.; Zamarreno, A. M.; Etienne, P.; Laine, P. Main binding sites involved in Fe(III) and $\mathrm{Cu}$ (II) complexation in humic-based structures. J. Geochem. Exp 2013,129, 14-17.

32. Gerke, J. Solubilization of Fe(III) from humic-Fe complexes, humic/Fe-oxide mixtures and from poorly ordered Fe-oxide by organic acids - consequences for P adsorption. Z. Pflanzenernahr. Bodenk 1993, 156, $253-257$.

33. Lucena, J. J. Fe chelates for remediation of Fe chlorosis in strategy I plants. J. Plant Nutr 2003, 26, $1969-1984$.

34. Tomasi, N .; Mimmo, T .; Terzano, R .; Alfeld, M .; Janssens, K .; Zanin L. Accumulation of nutrients in leaves of Fe-deficient cucumber plants treated with natural Fe-complexes. Biol Fert Soils 2014, 50, 973-982. 
35. Kumar, S.; Koh, J. Physiochemical, Optical and Biological Activity of Chitosan-Chromone Derivative for Biomedical Applications. Int. J. Mol. Sci 2012, 13, 6102-6116.

36. Lim, S.F.; Zheng, Y.M.; Zou, S.W.; Chen, J.P. Characterization of copper adsorption onto an alginate encapsulated magnetic sorbent by a combined FT-IR, XPS, and mathematical modeling study. Environ. Sci. Technol 2008, 42, $2551-2556$.

37. Zeng, S.; Cao, Y.; Sang, W.; Li, T.; Gan, N.; Zheng, L. Enrichment of Polychlorinated Biphenyls from Aqueous Solutions Using Fe3O4 Grafted Multiwalled Carbon Nanotubes with Poly Dimethyl Diallyl Ammonium Chloride. Int. J. Mol. Sci 2012, 13, 6382-6398.

38. Shi H, N.J.; Sakatsume, T.; Bandow, K.; Okudaira, N.; Uesawa, Y.; Sakagami, H.; Tomomura, M.; Tomomura, A.; Takao, K.; Sugita, Y. Quantitative Structure-Cytotoxicity Relationship of 3-(N-Cyclicamino)chromone Derivatives. Anticancer Res 2018, 38, 4459-4467.

39. Lewandowski, W.; Lewandowska, H.; Golonko, A.; Swiderski, G.; Swislocka, R.; Kalinowska, M. Correlations between molecular structure and biological activity in "logical series" of dietary chromone derivatives. PLoS One 2020, 15, 0229477.

40. Tang, Y.; Huang, Y.; Chen, Y.; Lu, L.; Wang, C.; Sun, T.; Wang, M.; Zhu, G.; Yang, Y.; Zhang, L. A coumarin derivative as a "turn-on" fluorescence probe toward Cd2+ in live cells. Spectrochim. Acta A Mol. Biomol. Spectrosc 2019, 218, 359-365.

41. Wani, M.A.; Singh, P.K.; Pandey, R.; Pandey, M.D. Coumarin-pyrene conjugate: Synthesis, structure and Cu-selective fluorescent sensing in mammalian kidney cells. J. Lumin 2016, 171, 159-165.

42. Yanar, U.; Babur, B.; Pekyilmaz, D.; Yahaya, I.; Aydiner, B.; Dede, Y.; Seferoglu, Z. A fluorescent coumarin-thiophene hybrid as a ratiometric chemosensor for anions: Synthesis, photophysics, anion sensing and orbital interactions. J. Mol. Struct 2016, 1108, 269-277.

43. Huang, J.; Yan, Z.; Qiu, P.; Mo, Y.; Cao, Q.; Li, Q.; Huo, L.; Zhao, L. A New Coumarin-Acridone Compound as a Fluorescence Probe for Fe3+ and Its Application in Living Cells and Zebrafish. Molecules 2021, 26, 2115.

44. Gast, K.; Fiedler, C. Dynamic and Static Light Scattering of Intrinsically Disordered Proteins, 2nd ed.; Uversky, V., Dunker, A., Eds.; Intrinsically Disordered Protein Analysis. Methods in Molecular Biology, Publisher: Springer, New York, 2012; Volume 896.

45. Tamborini, E.; Cipelletti, L. Multiangle static and dynamic light scattering in the intermediate scattering angle range Citation. Rev Sci Instrum 2012, 83, 093106.

46. Phanse, Y.; Ramer-Tait, A.E.; Friend, S.L.; Carrillo-Conde, B.; Lueth, P.; Oster, C. J., Phillips, G.J.; Narasimhan, B.; Wannemuehler, M. J.; Bellaire, B. H. Analyzing Cellular Internalization of Nanoparticles and Bacteria by Multi-spectral Imaging Flow Cytometry. J. Vis. Exp 2012, 64, 3884.

47. Graczyk, A.; Pawlowska, R.; Jedrzejczyk, D.; Chworos, A. Gold Nanoparticles in Conjunction with Nucleic Acids as a Modern Molecular System for Cellular Delivery. Molecules 2020, 25, 204.

48. Bayda, S.; Adeel, M.; Tuccinardi, T.; Cordani, M.; Rizzolio, F. The History of Nanoscience and Nanotechnology: From Chemical-Physical Applications to Nanomedicine. Molecules 2020, 25, 112.

49. Mukhtar, I.; Wu, S.; Wei, S.; Chen, R.; Cheng, Y.; Chen, L.; Chen, J.; Transcriptome Profiling Revealed Multiple rqu A Genes in the Species of Spirostomum (Protozoa: Ciliophora: Heterotrichea). Front in Microbiol 2021, 11, 3373.

50. Goncharuk, V.V.; Syroeshkin, A.V.; Zlatskiy, I.A.; Uspenskaya, E.V.; Orekhova, A.V.; Levitskaya, O. V.; Dobrovolskiy, V. I.; Pleteneva, T.V. Quasichemical description of the cell death kinetics of cellular biosensor Spirostomum ambigua for testing the biological activity of aqueous solutions. JWater Chem Tech 2017, 39, 97-102.

51. Palumbo, G.; Schiavon, M.; Nardi, S.; Ertani, A.; Celano G.; Colombo, C.M. Biostimulant Potential of Humic Acids Extracted From an Amendment Obtained via Combination of Olive Mill Wastewaters (OMW) and a Pre-treated Organic Material Derived From Municipal Solid Waste (MSW). Front Plant Sci 2018, 9, 1028.

52. Zhou, L.; Yuan, L.; Zhao, B.; Li, Y.; Lin, Z. Structural characteristics of humic acids derived from Chinese weathered coal under different oxidizing conditions. PLoS One 2019,14, 0217469.

53. Li, Y.; Guo, L.X.; Zhou, Q.Z. Characterization of Humic Substances in the Soils of Ophiocordyceps sinensis Habitats in the Sejila Mountain, Tibet: Implication for the Food Source of Thitarodes Larvae. Molecules 2019, 24, 246.

54. Klucakova, M.; Veznikova, K. The Role of Concentration and Solvent Character in the Molecular Organization of Humic Acids. Molecules 2016,21, 1410.

55. Melnikova, N.; Solovjevaa, O.; Vorobyovaa, O.; Solovyevab, A.; Peretyaginb, P.; Didenkob, N.; Korobkoa V. The Humic Acids of Peat. Physico-Chemical Properties and Biological Activity in Erythrocytes. Int. J. Pharm Sci. Rev. Res 2017, 45, 278-856.

56. Pant, K.; Singh, B.; Thakur, N. S. A Humic Matter Panacea for Cancer. IJTPR 2012, 4, 17-25.

57. Cagno, V.; Donalisio, M.; Civra, A.; Cagliero, C.; Rubiolo, P.; Lembo, D. In vitro evaluation of the antiviral properties of Shilajit and investigation of its mechanisms of action. J Ethnopharmacol 2015, 166, 129-34.

58. Kwon, P.S.; Oh, H.; Kwon, S.J. Sulfated polysaccharides effectively inhibit SARS-CoV-2 in vitro. Cell Discov 2020, 6, 50.

59. Gupta, A.K.; Gupta, M. Synthesis and surface engineering of iron oxide nanoparticles for biomedical applications. Biomaterials 2005, 26, 3995-4021.

60. Limbach, L.K.; Li, Y.; Grass, R.N.; Brunner, T.J.; Hintermann, M.A.; Muller, M.; Gunther, D.; Stark, W.J. Oxide nanoparticle uptake in human lung fibroblasts: Effects of particle size, agglomeration, and diffusion at low concentrations. Environ. Sci. Technol 2005, 39, 9370-9376.

61. Giachin, G.; Nepravishta, R.; Mandaliti, W. The mechanisms of humic substances self-assembly with biological molecules: The case study of the prion protein. PLoS One 2017, 12, 0188308. 
62. Yoon, H.Y.; Lee, J.G.; Esposti, L.D. Synergistic Release of Crop Nutrients and Stimulants from Hydroxyapatite Nanoparticles Functionalized with Humic Substances: Toward a Multifunctional Nanofertilizer. ACS Omega 2020, 5, 6598-6610.

63. Szabo, O.E.; Csiszar, E.; Toth, K.; Szakacs, G.; Koczka, B. Ultrasound-assisted extraction and characterization of hydrolytic and oxidative enzymes produced by solid state fermentation. Ultrason Sonochem 2015, 22, 249-56.

64. Reed, L.; Muench, H. A simple method of estimating fifty per cent endpoints. Am J Emerg 1938, $27,493-97$.

65. Xu, K.; Martinez, M.M.; Yang, B.; Guo, M. Fine structure, physicochemical and antioxidant properties of LM-pectins from okra pods dried under different techniques. Carbohydr Polym 2020, 241, 116272.

66. Odnovorov, A. I.; Grebennikova, T. V.; Pleteneva, T. V.; Garaev, T. M.; Uspenskaya, E. V.; Khodorovich, N. A.; Levitskaya, O. V.; Koldina, A. M. Physicochemical properties and biological hysicochemical properties and Hysicochemical properties and biological activity of the new antiviral substance. Int J App Pharm 2020, 12, 237-242.

67. Ismatullaev, A.; Taşın, S.; Usumez, A. Evaluation of bond strength of resin cement to Er:YAG laser-etched enamel and dentin after cementation of ceramic discs. Lasers Med Sci 2021, 36, 447-454.

68. Morozova, M. A.; Koldina, A. M.; Maksimova, T. V.; Marukhlenko, A. V.; Zlatsky, I. A.; Syroeshkin, A. V. Slow quasikinetic changes in water-lactose complexes during storage. Int J App Pharm 2021, 13, 227-232.

69. Syroeshkin, A.V.; Uspenskaya, E.V.; Pleteneva, T.V.; Morozova, M.A.; Zlatskiy, I.A.; Koldina, A.M.; Nikiforova, M.V. Mechanical Transformation of Compounds Leading to Physical, Chemical, and Biological Changes in Pharmaceutical Substances. Sci. World. J 2018, 8905471, 8.

70. Ph. Eur. 10.0: EDQM, 2019; Volume 2.2.32, pp. 39-42.

71. Vo, A.; Feng, X.; Smith, W.C.; Zhu, D.; Patel, M.; Kozak, D.; Wang, Y.; Zheng, J.; Ashraf, M.; Xu, X. Analyzing ophthalmic suspension particle size distributions using laser diffraction: Placebo background subtraction method. Int J Pharm 2021, 1, 120401.

72. Ishmatov, A.N.; Akhmadeev, I.R. The low-angle laser light scattering method in the study of pulse liquid atomization. Atmos Ocean Opt 2013, 26, 444-448.

73. Uspenskaya, E.V.; Pleteneva, T.V.; Kazimova, I.V.; Syroeshkin, A.V. Evaluation of Poorly Soluble Drugs' Dissolution Rate by Laser Scattering in Different Water Isotopologues. Molecules 2021, 26, 601.

74. Zhdanov, V.P. How the partial-slip boundary condition can influence the interpretation of the DLS and NTA data. J Biol Phys 2020, 46, 169-176.

75. Zlatskiy, I.; Pleteneva, T.; Skripnikov, A.; Grebennikova, T.; Maksimova, T.; Antipova, N.; Levitskaya, O.; Makarova, M.; Selivanenko, I.; Syroeshkin, A. Dependence of Biocatalysis on D/H Ratio: Possible Fundamental Differences for HighLevel Biological Taxons. Molecules 2020, 11;25(18):4173.

76. Mukhtar, I.; Wu, S.; Wei, S.; Chen, R.; Cheng, Y.; Liang, C.; Chen, J. Transcriptome Profiling Revealed Multiple rquA Genes in the Species of Spirostomum (Protozoa: Ciliophora: Heterotrichea). Front Microbiol 2021, 5, 574285.

77. Uspenskaya, E.V.; Pleteneva, T.V.; Syroeshkin, A.V.; Taravrina, I.V.; Preparation, characterization and studies of physicochemical and biological properties of drugs coating lactose in fluidized beds. Int J App Pharm 2020, 12, $272-278$. 